\title{
The relationship of disease severity, health beliefs, and medication adherence among HIV patients
}

Xin Gao

West Virginia University

Follow this and additional works at: https://researchrepository.wvu.edu/etd

\section{Recommended Citation}

Gao, Xin, "The relationship of disease severity, health beliefs, and medication adherence among HIV patients" (1999). Graduate Theses, Dissertations, and Problem Reports. 1054.

https://researchrepository.wvu.edu/etd/1054

This Thesis is protected by copyright and/or related rights. It has been brought to you by the The Research Repository @ WVU with permission from the rights-holder(s). You are free to use this Thesis in any way that is permitted by the copyright and related rights legislation that applies to your use. For other uses you must obtain permission from the rights-holder(s) directly, unless additional rights are indicated by a Creative Commons license in the record and/ or on the work itself. This Thesis has been accepted for inclusion in WVU Graduate Theses, Dissertations, and Problem Reports collection by an authorized administrator of The Research Repository @ WVU. For more information, please contact researchrepository@mail.wvu.edu. 


\section{The Relationship of Disease Severity, Health Beliefs, and Medication Adherence among HIV Patients}

\section{Xin Gao}

Thesis Submitted to the School of Pharmacy at West Virginia University

in partial fulfillment of the requirements

for the degree of

Master of Science

in

Pharmaceutical Systems \& Policy

David Nau, Ph.D., Chair

Sidney Rosenbluth, Ph.D., Co-Chair

Virginia Scott, Ph.D.

Carol Woodward, Pharm.D.

Department of Pharmaceutical Systems \& Policy

Morgantown, West Virginia

1999 


\section{ABSTRACT \\ THE RELATIONSHIP OF DISEASE SEVERITY, HEALTH BELIEFS, AND MEDICATION ADHERENCE AMONG HIV PATIENTS}

Xin Gao

Purpose. To investigate the relationship of disease severity, health beliefs, and medication adherence among HIV/AIDS patients.

Results. Seventy-two HIV patients were enrolled. There were no significant differences in patients' perceived severity of HIV/AIDS and perceptions of benefits and barriers of the treatment across three disease stages. However, patients who had greater experience with the disease (stage $\mathrm{C}$ ) perceived a higher risk to develop complications if they were not adherent compared to asymptomatic patients (stage A). Results also revealed that patients in stage B and C were more adherent to their medications compared to patients in stage A when regimen complexity was controlled. Finally, perceived susceptibility-inaction was positively related to medication adherence and difficulty in following doctors' instructions was negatively related to adherence.

Implications. Patients' medication taking behaviors can be improved by targeting issues specific to the individual patient and helping patients understand the negative consequences of poor adherence. 
For

Mom, Dad, and Shen 


\section{ACKNOWLEDGEMENTS}

There are many people who have made this study possible. I would first like to express my deepest gratitude to Dr. David Nau, my major advisor and Committee Chairperson, for his thoughtful guidance, patience and assistance as well as friendship throughout the course of this study. He is an inspiring teacher and I feel very fortunate to have trained underneath him. He has given me important skills I need for success. For this I am deeply indebted.

I would especially like to express my appreciation to Dr. Carol Woodward for her enthusiasm, support, and understanding throughout this study. Gratitude is also expressed to the other individual committee members of Dr. Sidney Rosenbluth, Dr. Virginia Scott for their helpful suggestions, encouragement, and guidance. I would like to thank Dr. Christine Teague and Dr. Michelle Forrest-Smith for their time and efforts in data collection. I am truly grateful to Dr. Suresh Madhavan for his concern and expert advice. Without their kind help, this study would have not been possible.

I would also like to extend my thanks to Dr. Kimberly Horn and Dr. Geri Dino, directors of the Office of Drug Abuse Intervention Studies in the Prevention Research Center at West Virginia University for their invaluable friendship and giving me wonderful research experience. In addition, I wish to express my appreciation to the staff of the School of Pharmacy, especially Marion and Shelia. I will be always grateful for their kindly support. Furthermore, I am thankful

to my friends and fellow graduate students, especially Aiman, Marie, Rohit, Ancilla, and Iftekhar for their suggestion, encouragement, and companion.

Finally, those who deserve the greatest credit for all that I have accomplished are my parents and my husband. They give me the lifetime of love, understanding, encouragement, and everything. They are always there taking care of me and giving me the strongest support. Words cannot express my appreciation. I dedicate this thesis to them and want them to know they are the best and I love them so much. 


\section{TABLE OF CONTENTS}

PAGE

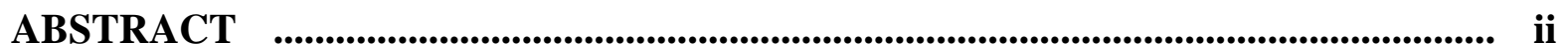

ACKNOWLEDGEMENTS ................................................................................................. iv

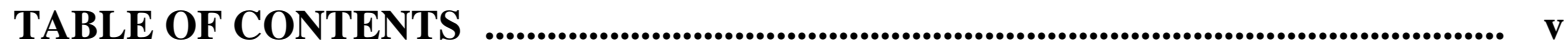

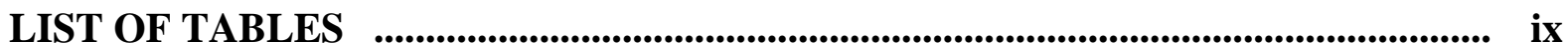

\section{CHAPTER I . INTRODUCTION}

Background of Problem ..................................................................................................... 1

Prevalence of Human Immunodeficiency Virus ............................................... 1

Stages of HIV/AIDS ............................................................................................... 2

Pharmacotherapy for HIV/AIDS ....................................................................... 4

Medication Adherence of HIV/AIDS Patients ................................................. 5

Clinical and Economic Impact of Non-adherence in HIV/AIDS .................. 6

Problem Statement ..................................................................................................... 7

Goal of Study .................................................................................................................... 7

Study Objectives ............................................................................................................. 8

Research Significance ............................................................................................................... 8

\section{CHAPTER II . LITERATURE REVIEW}

Defining Treatment Adherence ................................................................................... 9

Measuring Treatment Adherence ................................................................................. 11

Determinants of Treatment Adherence ..................................................................... 15

Physical Determinants of Non-adherence …......................................................... 16

Economic Determinants of Non-adherence ........................................................ 16

Social/Interpersonal Determinants of Non-adherence ................................... 17 
Psychological Determinants of Non-adherence ................................................ 18

Disease Severity and Treatment Adherence .............................................................. 25

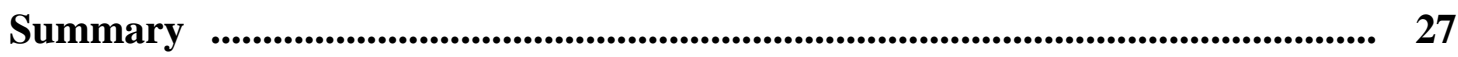

CHAPTER III. RATIONALE AND THEORETICAL FRAMEWORK

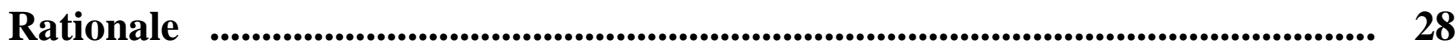

Theoretical Framework ................................................................................................... 29

Study Questions and Hypotheses ...................................................................... 30

\section{CHAPTER IV. METHODS}

Study Population .............................................................................................................. 32

Sample Selection .................................................................................................... 32

Sample Size ............................................................................................................ 32

Data Collection Procedures ........................................................................................ 33

Instrument Development and Validation .................................................................. 34

Item Construction ...................................................................................................... 34

Content Validity ................................................................................................. 39

Construct Validity .................................................................................................. 39

Reliability ................................................................................................................ 39

Data Analysis ................................................................................................................... 40

Analytical Methods for Objective 1-4 ..................................................................... 41

Analytical Methods for Objective $5 \quad$........................................................................ 41

Analytical Methods for Objective $6 \quad$.................................................................... 42

Limitations of the Study ........................................................................................... 42

Theoretical Issues $\quad$........................................................................................................ 42

Practice Issues ........................................................................................................... 43

\section{CHAPTER V. RESULTS}

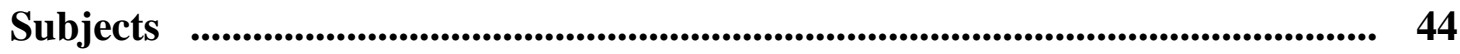

Study Variables ............................................................................................................... 48 
Construct Validity ............................................................................................................. 57

Scale Reliability ............................................................................................................. 59

Objective A to D Results .......................................................................................... 62

Objective E Results ..................................................................................... 64

Objective F Results ................................................................................................ 67

Influence of Ethnicity on Health Beliefs .................................................................... 69

\section{CHAPTER VI . DISCUSSION AND CONCLUSION}

Study Review .............................................................................................................. 75

Discussion of Results ....................................................................................................... 76

Health Beliefs of HIV Patients ........................................................................ 76

Relationship of Disease Severity and Health Beliefs ....................................... 77

Medication Adherence among HIV Patients ...................................................... 78

Relationship of Disease Severity and Medication Adherence ...................... 79

Relationship of Health Beliefs, Regimen Complexity, and

Demographic Factors with Medication Adherence ............................................... 80

Causal Links ........................................................................................................ 81

Recommendations for Future Research .................................................................... 81

Implications of the Study Results ……………………................................................. 82

Conclusions ......................................................................................................................... 84

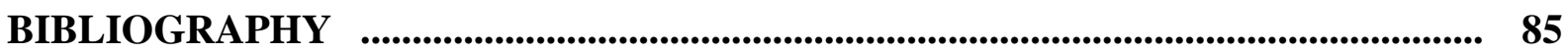

\section{APPENDICES}

A. CDC 1993 Revised Classification System for HIV Infection ................... 95

B. Clinical Categories Used in CDC 1993 Revised AIDS Surveillance Case Definition ...................................................................................................... 96

C. Indications for the Initiation of Antiretroviral Therapy in the Chronically HIV-Infected Patient .............................................................. 98

D. Cover Letter ........................................................................................ 99

E. Instruction for Pharmacists/Physicians …....................................................... 100 


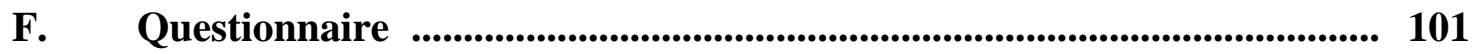

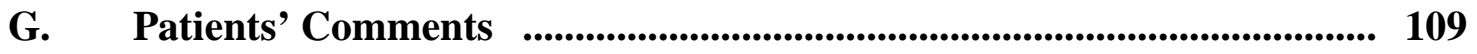

APPROVAL OF THE EXAMINING COMMITTEE 


\section{LIST OF TABLES}

TABLE

PAGE

1. Demographic Characteristics of Respondents 46

2. Clinical Characteristics of Respondents ................................................................. 47

3a. Study Variables - Health Beliefs .............................................................................. 49

3b. Study Variables - Regimen Complexity \& Medication Adherence ................. 53

4. Agreement of Three Measures for Medication Adherence .................................. 56

5. Factor Structure of Beliefs about HIV/AIDS and the Treatment .................... 58

6. Item-Total Correlation and Corrected Alpha ......................................................... 60

7. Scale Statistics and Reliability Coefficients .......................................................... 61

8. Health Beliefs among Patients in Different Disease Stages ................................. 63

9. Medication Adherence among Patients in Different Disease Stages ................ 65

10. Effects of Disease Severity on Medication Adherence ....................................... 66

11. The Relationship between Medication Adherence and Health Beliefs, Regimen Complexity, and Demographic Factors ................................................ 68

12. Comparison of Three Sites on Demographic and Clinical

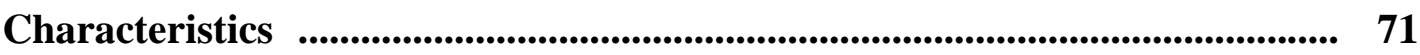

13. Patients' Composition of Three Sites by Gender and Race ............................... 72

14. Medication Adherence and Health Beliefs by Race .............................................. 73 


\section{CHAPTER 1 INTRODUCTION}

\section{Background of Problem}

\section{$\underline{\text { Prevalence of Human Immunodeficiency Virus }}$}

Human Immunodeficiency Virus (HIV), the cause of Acquired Immune Deficiency syndrome (AIDS), now infects more than a million people in the United States and millions more in other countries (World Health Organization, 1996). HIV is spread via sexual contact, exposure to contaminated blood or blood products, perinatally, and through contaminated breast milk. Once transmitted, the virus infects CD4 lymphocytes, leading to their destruction and immune system compromise. Ultimately, HIV infection culminates in the clinical manifestations known as AIDS. It encompasses a complex disease state characterized by progressive immune system dysfunction, opportunistic infections, and unusual malignancies (Quinn, 1995). Prior to 1994, it was predicted that $80 \%$ of patients with HIV would die from AIDS-complicating opportunistic infections and malignancies (Lane et al., 1994). Thus far, more than 300,000 persons have died from AIDS-related illnesses in the United States. Among those most affected are individuals between 25 to 44 years of age. In 1993, AIDS became the leading cause of death among this age group (Centers for Disease Control and Prevention, 1997).

AIDS also poses the greatest threat to public health of any communicable disease in contemporary times. It is unique in its combination of risk factors: the underlying disease process cannot currently be prevented or treated; the etiologic viral agent is noted for its propensity to exhibit phenotypic variability and to mutate easily, making the future development of vaccines or treatment more difficult; there is no finite incubation period, so carriers of the virus are chronically infectious; and the major risk groups lack appropriate and timely health care and are vulnerable to social prejudice and private discrimination (Michael, 1986).

Overall in the United States, there has been a stabilization in HIV prevalence and 
a slowing in AIDS incidence rates. However, a significant number of individuals (at least $40,000)$ continue to become infected annually, and among certain subpopulations the epidemic is growing (Rosenberg, 1995). The number of AIDS cases has grown disproportionately for women, African-Americans, and Hispanics. AIDS is becoming more prevalent in the southern United States, and heterosexual HIV transmission is more prominent now than ever before (Centers for Disease Control and Prevention, 1996). The population of HIV patients is becoming diverse. While the disease was initially found among intravenous drug users, male homosexuals, and hemophiliacs, it has become increasingly prevalent among men and women of all ages and social orientation.

The effort to reduce the spread of HIV has never stopped. The provision of care for persons with AIDS or other HIV-related conditions will place an increasing burden on the health care system of the United States for many years. Decreases in AIDS diagnoses, coupled with decreases in mortality, mean that an increasing number of people will need HIV medical care (Institute of Medicine, 1986). HIV/AIDS is increasingly viewed as a chronic, fatal illness requiring a continuum of preventive, acute, chronic, and palliative care services (Hanley, 1996). It is believed that if the care of these patients is to be both comprehensive and cost-effective, it must be conducted as much as possible in the community, with hospitalization only when necessary (Borfitz, 1994). Furthermore, less hospitalization enables a chronically ill individual to maintain a sense of autonomy and dignity in coping with his or her progressive physical deterioration. The current trend is to develop and promote self management of disease in HIV patients. Thus, patients' ability to manage their therapy becomes a critical issue.

\section{Stages of HIV/AIDS}

Active replication of HIV is the cause of progressive immune system damage in infected persons. In the absence of effective inhibition of HIV replication by antiretroviral therapy, nearly all infected persons will "suffer progressive deterioration of immune function resulting in their susceptibility to opportunistic infections, malignancies, neurologic diseases, and wasting, ultimately leading to death" (Enger et al., 1996; Haynes et al., 1996).

For adults in developed countries, the average time to develop AIDS after initial infection is about 10 to 11 years when only nucleoside analogue monotherapy or no 
therapy is provided (Enger et al., 1996). Some individuals develop AIDS within 5 years of infection $(\sim 20 \%)$, whereas others $(<5 \%)$ have sustained long-term (>10 years) asymptomatic HIV infection without decline of CD4+ T-cell counts to below 500 cells $/ \mathrm{mm}^{3}$. Only about 2 percent or less of HIV-infected persons seem to be able to contain HIV replication to extremely low levels and maintain stable CD4+ T-cell counts within the normal range for greater than 12 years (Haynes et al., 1996).

There are various staging systems for HIV disease. Stages of HIV/AIDS can be loosely described in terms such as early asymptomatic HIV disease, AIDS-related complex (ARC), and AIDS (Institute of Medicine, 1986). From 1987 to 1993, classification of HIV-related disease as AIDS depended upon the presence of one or more indicator conditions listed by the CDC (Centers for Disease Control and Prevention, 1992). These conditions, including a number of opportunistic infections, Kaposi's sarcoma, several types of lymphoma, HIV encephalopathy, and HIV wasting syndrome were used as AIDS indicators because they were very rare in the absence of compromised cell-mediated immunity due to advanced HIV infection. The case definition of AIDS was expanded on January 1, 1993 by the CDC in order to more accurately reflect the number of individuals with severe immunosuppression. This more frequently utilized system involves the assessment of indicator conditions as well as CD4+ lymphocyte count determinations. Indicator conditions are classified into categories A, B, and C. Category A includes patients without symptoms or those with persistent generalized lymphadenopathy. Category B includes signs or symptoms such as oral candidiasis, oral hairy leukoplakia, recurrent vaginal candidiasis, fever or diarrhea, and cervical dysplasia. Category $\mathrm{C}$ includes most of the opportunistic diseases associated with advanced HIV disease. These include Pneumocystis carinii pneumonia, esophageal candidiasis, cytomegalovirus disease, etc. CD4 lymphocyte counts are categorized as (1) more than 500 cells $/ \mathrm{mm}^{3}$, (2) between $200-500$ cells $/ \mathrm{mm}^{3}$, and (3) less than 200 cells $/ \mathrm{mm}^{3}$. According to the 1993 CDC classification system for HIV/AIDS, patients who have any indicator C condition or a CD4 lymphocyte count less than 200 cells/mm3 are considered to have AIDS (Appendix A \& B, Centers for Disease Control and Prevention, 1992). In current practice, laboratory parameters of plasma HIV RNA (viral load) and CD4+ T cell count, as well as the clinical conditions (symptomatic or asymptomatic) of the patient, are 
monitored together to identify the stage of HIV/AIDS and determine the corresponding treatments (Appendix C, Centers for Disease Control and Prevention, 1997).

Pharmacotherapy for HIV/AIDS

The goal of treatment for HIV infection is to maintain immune function in as near a normal state as possible, prevent disease progression, prolong survival, and preserve quality of life by effectively suppressing HIV replication. For these goals to be accomplished, therapy should be initiated, whenever possible, before significant irreversible immune system damage has occurred (Centers for Disease Control and Prevention, 1997). Recent findings regarding high-level viral replication favor early therapy using combinations of the two FDA-approved classes of medications: reverse transcriptase inhibitors (nucleoside and non-nucleoside analogues) and protease inhibitors (Enger, et al., 1996; Gasbrro, 1996). Based on current data, the most potent drug combination includes two nucleoside analogues and a protease inhibitor, although protease inhibitors are sometimes reserved for use in patients with high viral loads, symptomatic disease, or rapidly declining CD4 cell counts (Gulick, et al., 1996).

Five nucleoside reverse transcriptase inhibitors are commercially available: zidovudine (azidothymidine, AZT, ZDV, Retrovir ${ }^{\circledR}$, Glaxo Wellcome); didanosine (ddI, dideoxyinosine, Videx ${ }^{\circledR}$, Bristol-Myers Squibb); zalcitabine (ddC, dideoxycytidine, Hivid $^{\circledR}$, Hoffman-La Roche); stavudine (d4T, Zerit ${ }^{\circledR}$, Bristol-Myers Squibb); and lamivudine (3TC, Epivir ${ }^{\circledR}$, Glaxo Wellcome) (Gasbrro, 1996; Pietroski, 1996). Nonnucleoside reverse transcriptase inhibitors are highly selective for HIV-1, with little activity against HIV-2 (Pollard and Onorato, 1995). Nevirapine (Viramune ${ }^{\circledR}$, Boehringer-Ingelheim) and delavirdine mesylate (DLV, Rescriptor ${ }^{\circledR}$, Pharmacia \& Upjohn) are the only two commercially available nonnucleoside reverse transcriptase inhibitor (Pietroski, 1996; Pollard and Onorato, 1995). Few protease inhibitors have progressed to clinical trials because of bioavailability, protein binding, and toxicity issues. As of the end of 1996, three protease inhibitors were commercially available: saquinavir (SQV, Invirase ${ }^{\circledR}$, Hoffman-La Roche); ritonavir (Norvir ${ }^{\circledR}$, Abbott); indianvir (Crixivan $^{\circledR}$, Merck) (Pietroski, 1996; Anonymous, 1996); and Nelfinavir (Viracept ${ }^{\circledR}$, Agouron). In 1997, a combination of zidovudine and lamivudine (Combivir ${ }^{\circledR}$, Glaxo Wellcome) was introduced (Vogel, 1997). 
Adverse effects associated with reverse transcriptase inhibitors and protease inhibitors are relatively common. They include nausea, vomiting, headache, liver dysfunction, rash, peripheral neuropathy, diarrhea, abdominal discomfort, asthenia, and other problems (Pietroski, 1996; Glaxo Wellcome, 1996; Roxane Laboratories, 1996; Cohen and Noormohamed, 1996).

\section{Medication Adherence of HIV/AIDS Patients}

Patient non-adherence with prescription medications is a very serious issue. Studies have suggested that many patients do not take their medications as prescribed: they may modify the regimen themselves, or they may not fill/refill their prescriptions at all (Gibaldi, 1996; Haynes, et al., 1996; Osman, 1996; Pablos, et al., 1996). Nonadherence is especially common with drugs that do not produce an immediate positive reinforcement for continuing to take the medications properly, or drugs for which the side-effect are frequent and severe (Osman, 1996). Many drugs for AIDS do not produce an immediate, if any, improvement in the way the patient feels. In addition, many antiretrovirals are very toxic agents, and may cause severe adverse effects. Thus, persons with AIDS are very likely to modify or discontinue their drug therapy.

Drug regimen complexity is also associated with medication non-adherence (Bjornson, et al., 1992). Recent studies have shown that patients on monotherapy tend to develop resistance to the drug in 12 to 15 months' time, and that a better response is possible by combining two or more antiretrovirals that act on different points along the replication cycle of the HIV virus (Borfitz, 1994). Although combination antiretroviral therapy can reduce HIV viral load to undetectable levels in $80 \%$ of patients, patient adherence may be poorer with increased regimen complexity (Woodward, 1996). Finally, the common drugs used in the management of AIDS patients are very expensive. For example, the approximate monthly cost for Saquinavir, Indinavir, Ritonavir, and Nelfinavir are $\$ 590, \$ 502, \$ 677, \$ 557$, respectively (Tseng, 1998). Thus, monetary cost further decreases the likelihood of the patient obtaining and using the medications.

In summary, the perceived effectiveness of medications, adverse effects, complexity of regimens, and monetary cost of antiretroviral treatment contribute together to a relatively high non-adherence rate of drug therapy in HIV/AIDS patients. 


\section{Clinical and Economic Impact of Non-adherence in HIV Patients}

Patient adherence is essential to the success of drug therapy. Failure to adhere to therapeutic regimens is recognized as a major obstacle to obtaining effective medical care (Kaplan and Simon, 1990). The most powerful therapy will provide no benefit if taken incorrectly, and non-adherence may lead to the aggravation of illness or the emergence of multidrug-resistant HIV (Pablos, et al., 1996). Adherence is particularly important with antiretroviral agents. Continuous treatment is required for sustained viral suppression. Even short interruptions in therapy may result in enhanced HIV replication (Havlir and Richman, 1996).

While the costs of non-adherence may not always be apparent, they are substantial. Because of patient non-adherence and its widespread occurrence, health care costs are increasing (Colley and Lucas, 1993). Patient non-adherence has been identified as a major public health problem that imposes a considerable financial burden upon modern health care system (Donovan, 1995). A meta-analysis of relevant studies showed that approximately $5.3 \%$ of hospital admissions were related to medication nonadherence at a cost of more than $\$ 8$ billion in direct hospitalization costs. When indirect costs are included, the estimates of total expenditures resulting from non-adherence have ranged from $\$ 25$ billion to greater than $\$ 100$ billion (Sullivan et al., 1990). Another study shows that pharmacies lose more than $\$ 1.5$ billion in revenues each year as a result of patients' failure to refill prescription medications. This is especially true of medications for chronic conditions (Felkey, 1995).

For health insurers in particular, improving patient adherence is one key to decreasing overall health costs. Non-adherence is costly to health benefit plans because it may result in additional physician visits, emergency room visits, and hospitalizations. In brief, patient non-adherence is costly for disease management and patient outcomes. Because of the recognition that adherence to therapy is ultimately cost-effective, third party payers are now encouraging and compensating for adherence-related services, such as medication unit-dose packaging, drug regimen organization and review, starter doses, patient monitoring for drug effectiveness, and installation of electronic medication dispensers at home (Felkey, 1995). 


\section{Problem Statement}

Patients make critical decisions that affect the therapeutic outcome of their disease (Donovan and Blake, 1992). In this sense, patients share power with providers in the consumption process. Patients' beliefs about disease and medications may be crucial to their intentional adherence behaviors and may be very different than providers (Donovan and Blake, 1992). Thus, an apparently irrational act of non-adherence from the physician's or pharmacist's point of view may be a very rational action when seen from the patient's perspective. These incongruent perspectives may produce considerable frustration for patients and health care providers.

Patient's health beliefs and medication adherence may be affected by the severity of disease (Spilker, 1992; Graham et al., 1994; Smith, 1996). However, very little is known about how disease severity affects perceptions of health status, perceived benefits, and perceived barriers of treatment, and further affects decision-making regarding medication adherence among HIV/AIDS patients.

Symptoms can vary greatly in frequency and severity among HIV patients. Thus, there is likely to be considerable variability among HIV patients' perceptions of disease severity and progression, perceived benefits and costs of medication adherence, and other factors. Consequently, providing generalized information about HIV may not improve a patient's adherence behaviors. The effectiveness of an education intervention will be enhanced if the information targets the key perceptions of that patient. The effectiveness of adherence-gaining strategies may depend upon the extent to which they match patients' beliefs about health and medications. Therefore, knowing whether patients' beliefs about their health and medications change in a predictable way as their disease progresses may lead to the more effective design of drug therapy regimens and counseling approaches.

\section{Goal of Study}

This study will investigate the relationship of disease severity, health beliefs and medication taking behaviors among HIV patients. 


\section{Study Objectives}

1. Compare the perceived severity of HIV/AIDS among HIV patients in different disease stages.

2. Compare the perceived susceptibility to AIDS related complications among HIV patients in different disease stages.

3. Compare the perceived benefits of antiretroviral therapy among HIV patients in different disease stages.

4. Compare the perceived barriers to medication adherence among HIV patients in different disease stages.

5. Examine medication adherence of HIV patients with antiretroviral therapy in different disease stages.

6. Investigate the influence of regimen complexity and health beliefs on self-reported medication adherence.

\section{Research Significance}

To increase the effectiveness and minimize the costs of health care, it is important to understand patients' decision-making and the strategies that can enhance patients' medication adherence. A health care provider who understands a particular client's perspective has a tremendous advantage for helping the treatment. This study investigated how disease severity affects HIV patients' health beliefs and medication adherence. This information could be useful in helping health care providers understand patient motivations for discontinuing their antiretroviral treatment and helping patients collaboratively develop treatment regimens that facilitate adherence and optimize the outcomes of HIV/AIDS therapy. Finally, this study may help clinicians and researchers predict adherence rates of antiretroviral therapy, and develop well-aimed and effective interventions enhancing medication adherence in HIV/AIDS patients. 


\section{CHAPTER 2 LITERATURE REVIEW}

This chapter summarizes the results of an extensive review of the available literature regarding treatment adherence. The definition, measurement, and determinants of treatment adherence are included. The literature about the relationship of disease severity and treatment adherence among HIV/AIDS patients are also discussed.

\section{Defining Treatment Adherence}

Throughout this chapter, the terms "adherence" and "non-adherence" are used and considered equivalent to the terms compliance and noncompliance. Some have argued that although compliance and adherence are often used interchangeably (Dunbar et al., 1989; Sluijs and Knibbe, 1991; Leventhal and Cameron, 1987), important distinctions exist that reflect assumptions about the nature of patient-prescriber relationship. These assumptions are especially important in how they shape the expectations and interchanges between patients and prescribers. Given the nature of patient-prescriber relationship, the concept of "compliance" implies an obligation to passively obey, yield, or submit to a request or command from a higher authority (Meichenbaum and Turk, 1987; DiMatteo and DiNicola, 1982; Gerber, 1986). In contrast, the concept "adherence" does not imply the same passive obligation to obey, nor does it have the implication of punishment if a person is non-adherent. The activity implied with the concept adherence is one of voluntary choice in which a commitment is made to closely follow a plan or one's beliefs (Johnson, 1993).

Compliance has been defined as the extent to which a person's behavior, in terms of taking medications, following diets, or making other lifestyle changes, coincides with medical or health advice (Haynes, 1979). This is a very broad and theoretical definition. In reality, however, the concept of treatment adherence is far from being clear and straightforward. Defining adherence to complex medical regimens is especially difficult. 
Complex regimens require many different kinds of medication-taking behaviors, usually on a daily basis (Johnson, 1993). This is particularly true for persons with HIV infection who take combinations of antiretroviral medications. Because of differing bioavailability and half-lives, protease inhibitors may have to be taken at fixed intervals of either 8 or 12 hours around the clock, either with meals (e.g., saquinavir, nelfinavir, or ritonavir) or on an empty stomach (e.g., indinavir). Such a regimen usually also includes two other antiviral drugs (e.g., reverse transcriptase inhibitors) that will likely have different schedules. HIV patients may also be expected to make frequent clinic visits because they require close monitoring (Muma, 1995). Additionally, restrictions on diet and other aspects of the daily activities further complicate the treatment regimen. The sheer number of treatment-related behaviors makes complete treatment adherence difficult for persons with HIV.

While the Haynes definition of compliance is widely accepted, it has not escaped criticism. Johnson (1993) and Rudd (1993) argued that Haynes' definition of adherence was based on several assumptions such as proper diagnoses, effective treatment, and clear instructions. The physician's medical advice that was used by Haynes' definition as the standard to which the patient's behavior was compared was nonexistent or unclear for many complex treatment regimens. Thus the standard itself was suspicious according to Johnson and Rudd. They suggested that defining adherence require some sense of an ideal standard, clearly documented by the physician or by the investigator. However, their suggestion makes it almost impossible to define and compare adherence since the "ideal standard" is highly individualized and changes with time. For most adherence studies, it seems unnecessary to doubt the accuracy of diagnoses and prescriptions at the time adherence is defined. Regarding medication adherence, the only standard should be the prescription and related instructions to the patient.

In this study, treatment adherence was simplified as medication adherence. It focused only on adherence to the drug regimen rather than a comprehensive assessment of treatment adherence. Adherence in this study was defined as the extent to which HIV patients take their medications as prescribed. This definition was more specific and made the measures of adherence more understandable. 


\section{Measuring Treatment Adherence}

Various methods have been developed to measure adherence. These methods are generally categorized as either direct or indirect measures (Rudd, 1993). Direct measures include blood or urinary levels of medications, metabolites, or markers. Indirect measures include pill counts, prescription refills, self-report, clinicians' opinions, and medication-event monitoring systems (MEMS).

The direct biologic measures, like biologic assays of active drug or metabolite, confirm actual drug ingestion. However, assays are not feasible in most ambulatory settings due to their high cost and inconvenience for patients. Additionally, significant variance may exist between patients in their absorption, metabolism, and excretion of medications (Gordis, 1979). There is no clear causal linkage between lab parameters and adherence behaviors. Hence, assays provide little information about the consistency of medication taking.

Pill counts have been employed in many drug trials. This method requires subjects to return their pill supply at each visit so that the pills may be counted. Several obstacles interfere with standard pill counts (Rudd, 1993). These include subjects' changed behaviors due to concerns about being judged, forgetting to return pill vials, losing containers, sharing medication with other individuals, and storing medication in more than one place. The technique of pill counts is also very labor intensive, which makes this method impractical in most practice settings. Under this method, adherence is usually calculated as a percent discrepancy score which is the number of pills the patient had actually consumed divided by the number they should have consumed during a specified time interval (Finney et al., 1985; Samet et al., 1992; Foulkes et al., 1993; Putnam et al., 1994). It is calculated using the following formula [(prescribed doses missed doses $) \div$ (prescribed doses) $]$. Adherence may be reported as a continuous variable (e.g., percentage) or as a dichotomous variable (adherent/non-adherent) in which adherence is defined as being within $\pm 10 \%$ or $\pm 15 \%$ of the appropriate number of doses to be taken (Rudd, 1993).

The prescription refill method uses pharmacy dispensing records to monitor the prescribed dosing frequency and interval between prescription refills (Rudd, 1993). Prescription refill rate is a useful source of adherence information in population based 
studies when direct measurement of medication consumption is not feasible. However, this method may be confounded by patients obtaining refills at more than one pharmacy or by sharing medications with others.

Clinician's opinions are highly specific but relatively insensitive to patients' adherence behaviors (Rudd, 1993). Physicians may be both unaware of the importance of the relevant behavioral, psychological, and social aspects of care and lack of time, skills, or motivation to identify or manage these problems. Clinician's opinions can be used as references and combined with other measures.

One of the major improvements in assessing adherence rates has been the use of interview data (Morisky et al., 1986). Patient self-report method uses self-administered questionnaires or interviewers to obtain a patient's subjective evaluation of his or her own treatment adherence behaviors. It is one of the most frequently used methods in measuring medication adherence. The advantages of this method over other measures include its feasibility in all care settings, simplicity, and speed (Morisky et al., 1986). Disadvantages of this method include recall bias and subjectivity. The reliability of the self-report method may vary with the study variables such as the type or severity of disease, but frequently demonstrates acceptable validity and reliability (Rudd, 1993).

Green et al. (1975) first described a five-item self-reported scale measuring medication-taking behavior in outpatients being treated for high blood pressure. Later, a four-item scale with relatively high reliability was developed by Morisky et al. (1986) from the original five items: (1) Do you ever forget to take your medicine? (2) Are you careless at times about taking your medicine? (3) When you feel better do you sometimes stop taking your medicine? (4) Sometimes if you feel worse when you take the medicine, do you stop taking it? The theory underlying this measure was that drug errors of omission could occur in any or all of several ways: forgetting, carelessness, stopping the drug when feeling better, or starting the drug when feeling worse. By reversing the wording of four questions about the way patients might experience drug omissions, the sum of "yes" answers may provide a composite measure of non-adherence.

When using this scale, medication adherence is measured as an ordinal variable which is the number of "yes" answers. Then a categorical variable is created in order to assess adherence level: 0 item Yes means a high adherence level; 1 or 2 items Yes means 
a medium level; and 3 or 4 items Yes indicates a low adherence level. In Morisky et al.'s study, the scale demonstrated adequate internal consistency $(\alpha=0.61)$. Each item in the scale contributed significantly to the overall reliability coefficient, with a decrease in the alpha level if any single item was deleted. The validity of this scale is reflected by the relative balance of sensitivity (0.81) and specificity (0.44) of the scale (Gordis, 1996). The measurement scale developed in this study is simple and straightforward and easily conducted in clinic settings.

Electronic compliance monitors are a relatively new method (Rudd, 1993). The "monitor" is a computer chip embedded in the cap of a prescription container. It records the actual time at which the container was opened and medication was presumably taken. The monitor stores multiple days worth of data and can provide a time tracing that becomes the matrix on which the investigator places other observations, measurements, and potential predictors in search of associations. Hence, the monitors assess medicationtaking events on a dynamic basis. Such electronic compliance monitoring has become the new "gold standard" for pharmacologic treatment studies and other adherence measures. Theoretically, the monitors could provide a probe for factors that facilitate, cue, or inhibit specific occasions of dispensing and presumably consuming medications. However, it remains possible that a patient might open and close the monitor and not actually take the medication. Also, this method is too expensive to be applied to large samples.

For studies within the HIV/AIDS population, the most common methods for measuring adherence were self-report, biologic assays, and a combination of the two. Lim examined the use of serum drug levels to assess adherence to study medication in a clinical trial (Lim, 1992). Zidovudine adherence was estimated from serum levels. However, it is unusual to analyze blood samples directly for zidovudine levels in order to measure zidovudine adherence. Although this direct method is more accurate, the cost of the test makes it prohibitive. Since a side effect of zidovudine treatment is a massive elevation of mean corpuscular volume (MCV) of erythrocytes, macrocytosis is the usual biologic method for assessing long-term adherence (Sande and Volberding, 1990; Samet et al., 1992; Muma et al., 1995). Broers et al. (1994) combined MCV test and physicians' estimates to measure drug users' adherence with zidovudine treatment. Results showed 
that the physicians' estimates' of their patients' adherence correlated well with MCV values. However, both clinicians' opinions and MCV tests are highly specific but relatively insensitive to the adherence information (Sande and Volberding, 1990; Samet et al., 1992; Muma et al., 1995).

Several studies have shown that the self-reports may also be reliable and valid methods of assessing HIV medication adherence (O'Connor, et al., 1992; Samet et al., 1992; Geletko, et al., 1995; Muma, et al., 1995). In the study conducted by O'Connor, medication adherence was measured by documentation that medication was dispensed monthly and patients' report that it was taken. In Geletko's study, patients' self-reports regarding their medication use were verified with the medical records.

In another study of zidovudine adherence among HIV patients, patients' selfreport verified by MCV method was used (Muma et al., 1995). Adherents were defined to include those who took zidovudine as prescribed and whose MCV of erythrocytes had to be more than $100 \mathrm{fl}$, which is the case when zidovudine is consistently taken. Graham et al. (1994) reported that when using rise in MCV as the gold standard, validity of selfreports for zidovudine use is high (sensitivity $=88 \%$, specificity $=91 \%$ ). They then expanded this conclusion to the self-report method for other related drugs as a proof of study validity.

Berod et al. applied prescription refill method to measure outpatient adherence with zidovudine therapy in a community-based study (Berod and Simon, 1993). Since their pharmacy department was the only pharmacy in French Polynesia that dispenses zidovudine for outpatients infected with HIV, the problem of multiple-pharmacy prescription refills did not exist. This is a good example for choosing an appropriate measurement based on the nature of the study (community-based) and the actual local condition.

In summary, no measure of adherence proves perfect. The advantages of cost, convenience, and acceptability have generally served as counterweights to accuracy, nonreactivity, and comprehensiveness. There are critical challenges in research related to adherence measurement. It has not been possible to find an absolute "gold standard" measurement that can be applied to all kinds of related research. Choosing the most appropriate method of adherence measurement will depend on a good understanding of 
the nature of study and the practical implications of each technique.

\section{Determinants of Treatment Adherence}

Treatment adherence is a complex human behavior that is influenced by a variety of factors. Much research has been conducted in efforts to identify the factors that influence treatment adherence and methods of improving adherence behavior. Through 1984, approximately 700 studies had been conducted, using more than 200 variables to assess the determinants of adherence behavior (Morisky et al., 1986). Various sources report that approximately $25-60 \%$ of patients do not adhere to their prescribed medication regimens, especially when life style changes are required as with HIV medications (Becker \& Maiman, 1980; Friedman \& DiMatteo, 1989; Muma et al., 1995). Documented explanations for a lack of adherence with therapeutic regimens in general have included disease factors, patient personality characteristics, environmental and situational barriers, complex medical regimens, patients' health beliefs, and an inadequate clinician-patient relationship (Rudd et al., 1979; Haynes, 1979; DiMatteo \& Friedman, 1982).

To date, there is limited research that describes the dimensions associated with HIV medication adherence. Most research has focused on zidovudine adherence (Berod and Simon, 1993; Broers et al., 1994; Muma et al., 1995; Geletko et al., 1995; Lim, 1992). Meanwhile, some studies examined medication adherence in HIV positive intravenous drug users (IVDUs) due to the fact that IVDUs often have significant medical problems and are in need of comprehensive primary care in addition to drug treatment (O'Connor et al., 1992). Since few studies have investigated the issue of HIV medication adherence, a small number of dimensions have been identified to explain adherence. The study by Samet et al. (1992) identified that adherence was associated with a diagnosis of AIDS or ARC, the number of medications taken with zidovudine, and the belief that zidovudine could prolong life. Other reasons proposed by clinicians and patients to explain zidovudine non-adherence include the high cost of antiretroviral medication, toxicity associated with the drug, patients' beliefs about their disease and medications, misleading information from the media, and minimal or incorrect education on taking the medication (Baker \& Muma, 1991). Broers's (1994) study also identified 
substance abuse, unstable housing, and concurrent psychiatric problems as contributors to non-adherence. Disease severity was also reported to affect treatment adherence and patient perceptions (Smith, 1996; Spilker, 1992).

Morris and Schulz (1993) conducted a comprehensive review on the determinants of treatment adherence from the patients' perspective. They recognized that patients evaluate medication based not only on its clinical effectiveness, but also on how it affects all aspects of their lives. Four determinants of non-adherence were summarized in their study: physical, economic, social or interpersonal, and psychological determinants.

\section{Physical Determinants of Non-adherence}

Physical experiences with a disease or medications can alter a patient's pattern of medication taking. For example, a qualitative study of illness experiences found that symptom control significantly influenced the adherence to treatment guidelines (Hunt et al., 1989). Morris and Schulz (1993) showed how physical responses to treatment affect medication taking. They found that an expected response to treatment, such as a decrease in pain, may actually improve adherence. Alternatively, negative experiences with medications, can result in non-adherence. In the studies they reviewed, non-adherence from the patient's perspective was intentional and rational. Patients evaluated the effectiveness of the medication to help them decide what medication to take and when. Patients may alter their medication regimen to control symptoms or avoid side effects in an attempt to improve their quality of life. Thus, physical responses may influence medication taking behaviors.

\section{Economic Determinants of Non-adherence}

The rising costs of medical care may be an important explanation of nonadherence. Boza et al (1987) reported that financial problems might be a major cause of noncompliance in elderly and poor patients. In Chubon's study (1989), many patients expressed concern about the cost of medications and medical care. Some of them were forced to go without medications until they had acquired the money to purchase. Fear of the monetary expense or loss (such as absence from work due to required clinic visit) associated with obtaining medical care may be inversely associated with adherence. However, the effect of cost and medical insurance on compliance is inconsistent (Cooper et al., 1982; Morris and Schulz, 1993). In the study by Cooper et al. (1982), only 6\% of 
the elderly respondents reported that a medication was not available or that they could not afford it.

The inconsistency in the effect of cost on adherence in the literature may be due to the various populations and type of medicine studied. Variations in insurance policies and state Medicaid programs such as prescription limits, may also influence the price sensitivity of medications. People may value medications differently depending on the condition being treated (Morris and Schulz, 1993).

For HIV/AIDS patients, the common drugs such as ZDV and SQV are very expensive. On the other hand, the monetary cost may not be a very important issue for some patients since HIV infection is a life-threatening disease (Samet et al., 1992). Medication price sensitivity may change with disease severity and the amount of out-ofpocket payment. The influence of monetary cost on medication adherence remains unclear for HIV population.

\section{Social/Interpersonal Determinants of Non-aherence}

Three dimensions can be summarized from the many social factors employed in adherence-related studies: patient-practitioner relationship, social influence, and demographic factors.

The effects of patient-practitioner relationship on adherence behaviors have been studied by many researchers for a long time. Coe and Wessen (1965) have suggested that numerous aspects of the physician-patient interaction, such as impersonality and brevity of encounter, negatively influence patient behavior. Stimson (1974) has suggested that a physician's actions may affect how some people view medications. Most people have some expectations or beliefs about their treatment such as the expected type, cost, and amount of medication needed to produce a desired outcome. Treatment adherence of patients is associated with how well these expectations can be satisfied. Lack of communication (both cognitive and emotional) is usually held to be the problem (Becker and Maiman, 1975; Donovan and Blake, 1992; Remien, 1998). If it is difficult for patients to understand their treatment or follow the instructions, it may cause misunderstanding and inappropriate expectations. In a study conducted by Stall et al. (1996) among gay/bisexual men with HIV, patients who trusted their physicians were more likely to follow the standard of care guidelines for HIV. Another study by Morse et 
al. (1991) indicated that patients who saw their nurses as supportive were more adherent to their medication.

Remien (1998) also pointed out that the relationship between patients and other medical persons is very important. Pharmacists play an essential role in helping patients understand their treatment regimen and the potential negative consequences of poor adherence, cooperating with physicians to simplify treatment regimens, and providing practical suggestions to help patients remember to take all doses of medications.

In addition, studies have shown that several social factors, such as friends and family members' suggestion or behaviors (Stall et al., 1996; Foulkes, 1993), living alone (Besch et al., 1997; Morse et al., 1991), having an unstable social environment (Morse et al., 1991), caring for sick relatives (Muma et al., 1995), and being homeless (Samet et al., 1992) were associated with lower adherence. Conversely, a good relationship coupled with consistent support, particularly from a spouse or significant other (Evans et al., 1986; Somer and Tucker, 1988; Erdman et al., 1993), was associated with better adherence.

Treatment adherence is also associated with extremes of age (very young patients or geriatric patients) (Becker and Maiman, 1975). In general, studies show that adherence is not consistently related to gender, intelligence, education, or marital status (Becker and Maiman, 1975). For the HIV population, one study found ethnicity (black race, independent of drug use or education) (Muma et al., 1995) associated with nonadherence, but three others did not (Eldred et al., 1997; Besch et al., 1997; Morse et al., 1991). In addition, gender and age may not be related to treatment adherence in the HIV population (Remien, 1998).

\section{Psychological Determinants of Non-adherence}

Health researchers have long attempted to understand the psychological factors that influence treatment adherence behaviors and relevant decisions. A number of belief-based theoretical models have been developed as a way to understand and explain health related behaviors. These include the Andersen Behavioral Model (ABM: Andersen and Newman, 1973; Andersen, 1995); the models rooted in the Subjective Expected Utility theory (SEU: Edwards, 1954) such as the Theory of Reasoned Action (TRA: Fishbein and Ajzen, 1975; Ajzen and Fishbein, 1980) and the Theory of Planned 
Behavior (TPB: Ajzen, 1985); the Health Belief Model (HBM: Rosenstock, 1966; Becker and Rosenstock, 1987); and recent revisions of the HBM (Ronis, 1992; Nau, 1997). These theories and models have made tremendous contributions to understanding health behaviors although none are perfect predictors of health behavior.

The Andersen Behavioral Model incorporates sociodemographic, economic, and social psychological variables in order to explain the use of health services (Andersen and Newman, 1973; Andersen, 1995). These variables are conceptualized as predisposing, enabling, or need factors for the use of health services. Predisposing factors include immutable demographic variables and the health beliefs that are embedded in a person's attitudes, values, and knowledge. Enabling factors include access, availability, and acceptability. Need factors include health status, symptomatology, or perceived health status. The purpose of this model is to discover conditions that either facilitate or impede utilization of medical care. It is a very broad measure of access to medical care. Consequently, it has been employed often to study the use of health services in general due to the comprehensive nature of its variable set.

The Theory of Reasoned Action (TRA) has been widely used by socio-behavioral researchers. The Theory of Planned Behavior (TPB: Ajzen, 1985) is an extension of TRA which has also been called the Behavioral Intention Model (TRA and BIM: Fishbein 1967; Fishbein and Ajzen 1975). The TRA and TPB postulate that the most immediate determinant of a person's behavior is a behavioral intention. Influencing behavior is achieved through influencing one's intentions. The TRA models behavioral intention as a function of two sets of variables, whereas the TPB models intention as a function of three sets of variables. The two common variable sets are "attitude" and "subjective norm". The attitudinal component is taken to be a function of a person's beliefs about the outcome of the behavior. Attitudes are conceptualized as being composed of personal evaluations of each outcome $(i)$ of the behavior multiplied by the strength of a belief about this outcome $\left(\sum \mathrm{e}_{i} \mathrm{~b}_{i}\right)$. The sum of these multiplicative components is then held to be an indirect measure of the attitude towards the behavior. The subjective norm refers to a summary statement of normative social influences. It is conceptualized as the sum of products of normative beliefs attributed to each significant referent person $(j)$ and the motivation to comply with these expectations $\left(\sum \mathrm{nb}_{j} \mathrm{~m}_{j}\right)$. There 
is no difference between the TPB and TRA in the first two components. However, the TPB adds a third determinant called perceived behavioral control.

Perceived behavioral control is the degree to which people perceive themselves to control their behavior. This additional component takes non-volitional behaviors into account. It is based on an evaluation of the power of factors likely to facilitate or inhibit the behavior/action weighted by their frequency of occurrence. Both internal control factors, such as information and personal abilities, and external control factors, such as opportunities and barriers, are included in this determinant.

TRA and TPB appear to be extensions of Edwards' Subjective Expected Utility theory (van der Plight, 1994). The SEU theory is a mathematical model of decision making in which people compare the expected utility (desirability) of alternative behaviors and choose the action with the highest SEU. The SEU of a behavior is the perceived probability of a specific outcome or consequence of the behavior multiplied by the desirability of that outcome. The mathematical expression is:

$$
\mathrm{SEU}_{j}=\sum_{i} \mathrm{P}_{i j} \mathrm{U}_{i j}
$$

where $\mathrm{SEU} j$ is the subjective expected utility of behavior $j, \mathrm{P} i j$ is the perceived probability of outcome $i$ of behavior $j$, and Uij is the subjective utility or desirability of each possible outcome $i$ of behavior $j$. Once behavioral alternatives and the relevant beliefs have been identified, researchers can make specific predictions about the behavior and the decision making process based on the SEU model.

Past research on TRA, TPB, and SEU has found them quite useful in predicting behavioral intentions. However, various limitations of these theories have also been identified (Leventhal and Cameron, 1987; Ronis, 1992). These theories do not provide clear explanations and predictions on actual behaviors. They do not specify which outcomes or beliefs are most relevant to a given decision and further to a behavior. Additionally, it is not easy to apply these theories in health fields. Variables such as the norms regarding the acceptability of performing the action, the motivation to comply with these norms, and the probabilities for all outcomes are difficult to define completely and measure validly in predicting a health-related behavior. People may use simpler decision rules than those espoused by involved in these theories (Nau, 1997).

The most widely used rational belief theory for explaining health behaviors is the 
Health Belief Model (HBM) which was first introduced by Rosenstock (1966). It has been frequently used as the major theoretical or organizing framework for explaining and predicting adherence to health and medical care recommendations (Janz and Becker, 1984; Morse et al., 1991; Geletko et al., 1995; Muma et al., 1995). Unlike ABM, SEU, TPB and TRA, it is a psychological theory originally aimed at health-related behaviors. Briefly stated, the HBM is composed of four basic belief dimensions: (1) Perceived probability of a threat, or the subjective perception of vulnerability to a particular health condition; (2) Perceived severity of the threat, which includes evaluations of both health and social consequences; (3) Perceived benefits, or the feasibility and efficacy of the particular health behavior; and (4) Perceived barriers, or impediments to undertaking the behavior. The Health Belief Model posits that patients' perceptions of susceptibility to and severity of a given disease, as well as perceived benefits and barriers to a particular treatment or procedure, are predictive of patient adherence to a therapeutic regimen. A person's tendency to take an action is hypothesized to be increased by high susceptibility, high severity, high benefit, and low barriers. HBM also recognizes various "cues to action", which include mass media, interpersonal communications, and other stimuli. Additionally, the value one places on health (Lau et al., 1986), self-efficacy (Bandura, 1977) and health locus of control (Wallston and Wallston, 1981) have been included in derivations of the model.

The HBM has provided a useful framework for understanding preventive health behaviors, such as skin cancer protective behavior (Carmel et al., 1994), breast selfexamination behavior (Ronis and Kaiser, 1989), dental flossing behavior (Ronis, 1992), participation in health screenings (e.g., Ronis and Harel, 1989; Aiken et al., 1994; Blalock et al, 1990), and immunizations (Becker and Maiman, 1975). The HBM has also been used in predicting sick-role behaviors which are actions taken to restore good health or prevent disease progression, such as the compliance to health recommendations and therapeutic regimens (e.g., Becker, 1974; Becker and Maiman, 1975; Janz and Becker, 1984; Morse, et al., 1991; Geletko, et al., 1995; Muma, et al., 1995). Many investigators have found it to provide demonstrable explanatory and predictive values. However, several limitations of HBM exist and should not be ignored. In the HBM, evaluations of the outcomes/consequences of the behavior are not explicitly represented and, as a result, 
may not be measured. Furthermore, the model does not clearly state the relations among the four heath beliefs or the relative importance of each belief in the decision making process. Similarly, the relationship between health beliefs and the various cues of action such as disease severity has not been stated clearly. Finally, the perceived susceptibility and perceived severity (the combination of these two variables has also been referred to as perceived threat in some studies), whether used independently, or with other health belief variables, have consistently been shown to be less than ideal predictors of a behavior (Conner and Norman, 1994).

The deficiencies of HBM have led some researchers to revise HBM. Ronis suggests that the HBM be combined with SEU theory (Ronis and Harel, 1989; Ronis, 1992). In this combined model, perceived susceptibility is equated with the perceived probability of an outcome $\left(\mathrm{P}_{i j}\right)$ and perceived severity is equated with the (dis)utility associated with that outcome $\left(\mathrm{U}_{i j}\right)$. Thus, according to the SEU theory, the expected utility of taking an action is linked to the concepts of perceived severity and perceived susceptibility. At the same time, Ronis suggested that the concept of benefits include all anticipated desirable consequences of an action and the concept of costs include all anticipated undesirable consequences of an action. It is very important that in the integrated model, all perceptions of severity, susceptibility, benefits and costs are defined by comparison to inaction or other behaviors. Thus, the criterion of decision making is quantified by the value change of SEU and the behavioral alternative with the highest SEU is enacted. This is reflected in the mathematical expression: $\Delta \mathrm{SEU}=\Delta \sum \mathrm{P}_{i j} \mathrm{U}_{i j}$, and more specifically, $\Delta \mathrm{SEU}=\left(\Delta \sum \mathrm{P}_{i j} \mathrm{U}_{i j}\right)_{\text {benefits }}+\left(\Delta \sum \mathrm{P}_{i j} \mathrm{U}_{i j}\right)_{\text {costs }}$. The benefits will include all outcomes/consequences with positive $\Delta \mathrm{P}_{i} \mathrm{U}_{i}$ value and similarly, the costs will include all outcomes/consequences with negative $\Delta \mathrm{P}_{i} \mathrm{U}_{i}$ value. Note that, due to the multiplicative combination rule in this SEU formula, a reduction in severity $\left(\Delta \mathrm{U}_{i}>0\right)$ produces perceived benefit only if people believe they are susceptible to the disease $\left(\mathrm{P}_{i} \neq 0\right)$.

Ronis also suggests that the concepts of susceptibility and severity need to be refined in this combined model. They need to be made conditional on the alternative actions or inaction. For example, it is critically important to distinguish between (a) susceptibility to a disease/disease progression when an action (preventive action or adherence to the regimen) is taken and (b) susceptibility to a disease/disease progression 
when the action is not taken. Therefore, perceived susceptibility and severity should be evaluated in a given condition in which the action (e.g., adhering to the treatment) will or will not be taken. High susceptibility given inaction is associated with higher possibility of taking the action and high susceptibility given action is associated with lower possibility of taking the action. Similarly, high perceived severity given inaction is associated with higher possibility of taking the action and high severity given action is associated with lower possibility of taking the action (Ronis, 1992).

The revised HBM was well supported by the studies of breast cancer screening behavior (Ronis and Harel, 1989), breast self-examination behavior (Ronis and Kaiser, 1989), and dental flossing behavior (Ronis, 1992). However, the failure to find the interactive influence of perceived severity and perceived susceptibility on perceived benefits in these studies impairs the reliability of the multiplicative combination of perceived severity and perceived susceptibility.

The implication of Ronis' work is obvious. He found that conditional perceptions of susceptibility and severity were related to the perceived benefits of the behavior and the behavioral intentions. This is consistent with the suggestion of the TRA (Ajzen and Fishbein, 1980) that measurements of their behavioral beliefs and behaviors should correspond closely in terms of the specific action, context, time, and target. The failure to use conditional measurements may explain the previous inconsistent findings for perceived severity and perceived susceptibility.

Another modification suggested by Nau (1997) is combining the perceived susceptibility and perceived severity to form a global perception of the "health threat" under a consideration that people may not form truly independent perceptions of susceptibility and severity when evaluating a health problem. This conception has also been supported by other researchers (Janz and Becker, 1984; Schwarzer, 1992; van der Plight, 1994). Nau (1997) also suggests that the concept of perceived threat should be measured as conditional upon engaging in the specified behavior. This should enhance the specificity of the measured belief. The concept of "perceived benefit" he used is based on a potential need for the action (e.g., taking a medication or using a health service). Thus, any reduction in health threats will produce perceived benefit by reflecting a satisfied need. Then the costs and benefits of taking an action are weighed to 
determine the value of that behavior. Action is postulated on the balance between benefits and costs, in which the balance is conceptualized as "perceived value" (Dodds and Monroe,1985; Wood and Scheer, 1996).

In a study of the use of pharmaceutical care services, Nau (1997) pointed out that different diseases may produce more variability in perceptions of severity. For example, Breast cancer is likely to be perceived as severe by nearly all women and gingivitis is likely to be perceived as mild by most persons. On the contrary, people with HIV infection or asthma have various symptoms, which could increase the variability in their perceived severity. Thus, Nau suggested that the lack of variability in persons' perceptions of the severity of a particular health problem may be an explanation of why perceived severity (or perceived threat) has played a weak role in predicting certain health behaviors.

Nau (1997) also suggested that perceived benefits reflect the individual's assessment of the extent to which engaging in the preventive behavior will produce a desired health benefit. This health benefit could be a reduction in the likelihood of developing a health problem. Hence, the extent to which one believes that taking an HIV medication will reduce his/her likelihood of developing HIV-related problems could be the basis for the perceived benefit of the HIV medication.

Morris and Schulz used the self-regulation theory developed by Conrad (1985) and Hunt et al. (1989) to understand psychological aspects of non-adherence. Selfregulation theory suggests that behaviors such as medication non-adherence are likely influenced by varying multiple factors (e.g., psychological, social, family, and physiological factors), and thus require self-regulation or self-control for adherence under the varying conditions that these factors create. Self-regulation theory asserts that execution of a target behavior (i.e., taking of medication properly) requires (1) being motivated to do the behavior by internal and/or environmental stimuli, (2) perceiving that one has control over the behavior, and (3) perceiving support of one's efforts to do the behavior. In fact, there are many overlaps between self-regulation and components of some other theories (e.g., cues to action from Health Belief Model and perceived behavioral control from Theory of Planned Behavior). 


\section{Disease Severity and Treatment Adherence}

As mentioned before, studies have shown that medication taking behaviors are related to the severity of disease (Spilker, 1992; Graham et al., 1994; Smith, 1996). Patients with different symptoms of disease and/or patients with different diseases (fatal or mild chronic) may have different responses to treatment. Disease severity is also shown to influence health beliefs and typically treated as a cue to action in most studies using HBM (Geletko, etc., 1995; Conner and Norman, 1994). However, the relationship between disease severity and other belief factors in HBM is not clear. The relative importance of disease severity in the model has also not been well studied. Cues to action (such as media messages and sociodemographic factors) are generally considered to be outside the model and only influence behavior via their effects on beliefs (Liska, 1984).

Most of the medication adherence literature focuses on illnesses that tend to be chronic in nature and not immediately life threatening, such as hypertension, heart disease, and diabetes mellitus (Morse, et al., 1991). HIV infection is a more serious illness, although recently there have been some medications developed to prolong and increase the quality of life.

Another aspect of the HIV infection, is that symptoms can vary greatly in frequency and severity among HIV patients. In the early stages of the disease, for example, there may be no symptoms experienced by the patient and the consequences of terminating treatment are delayed (Griffith, 1990). Hence, some patients in this stage may be more sensitive to the side effects of the medication despite its benefits and may not feel any discomfort soon after discontinuing their medications.

Due to the nature of the disease and the limited number of studies in this area, it is difficult to find research covering patients in all different stages of HIV infection. Morse et al. (1991) conducted a study on determinants of compliance of ZDV for asymptomatic HIV-infected patients. They found more adherent subjects lived further from their treatment site, did not live alone, saw their study nurse as supportive, and were more likely to depend on a significant other for a wide range of social, economic, and emotional support. On the contrary, Geletko et al. (1995) studied the reasons for discontinuation of ZDV therapy among patients only with AIDS or AIDS-related 
complex (ARC). Results indicated that lack of perceived benefit from zidovudine therapy and adverse effects of the drug were associated with discontinuation of zidovudine. No clinical category information using CDC defined classification for HIV/AIDS were provided in these two studies. In Muma et al.'s study (1995), only patients with mild symptoms of HIV disease were enrolled into the study (CDC group A1, A2, B1, B2), and no patients that met the CDC criteria for AIDS were included. They found non-adherence was related to attitudes and beliefs about zidovudine: patients who had problems taking zidovudine or were skeptical about the value of zidovudine were less adherent. However, the results of these studies could be biased since patients' beliefs, attitudes, and adherence behaviors may vary with their disease status and experiences. The studies conducted by Morse et al. (1991), Geletko SM, et al. (1995) and Muma RD, et al. (1995) did not address the impact of disease severity on health beliefs and medication taking behaviors.

A study conducted by Samet et al (1992) included patients with non-symptoms, mild symptoms and patients with AIDS or ARC. They did find adherence behaviors were associated with the diagnosis of AIDS or ARC and the patient belief that zidovudine prolonged life. However, there was no consideration on the relationship between the diagnosis (stage of HIV infection) and the belief of the patient. A study by Smith (1996) defined stages of HIV infection according to the CDC standard classification. He found a significant association between CD4+ cell count, having a usual source of health care, ambulatory visits, and use of antiretrovirals at each of the three stages of HIV disease. Smith and colleagues examined the multiple interactions between several variables and the stage of HIV disease and did find an association between antiretroviral use and predisposing or enabling characteristics such as gender, income, insurance status, race, and counseling/group support attendance. However, they did not use the CDC categories to differentiate the patients' experience with the clinical complications of HIV nor did they examine how health beliefs change over the course of HIV/AIDS.

Among HIV patients, the relationship of adherence and health status, including disease severity, remains unclear. This is a problem that is not isolated to the HIV literature (Johnson, 1993). Additional work is needed to assess this relationship. 


\section{Summary}

As can be seen from the previous review, treatment adherence behaviors are complex and difficult to define, measure, and predict. Many factors have been identified to influence treatment adherence. These include disease severity, personal preferences, environmental and situational barriers, complex medical regimens, and patients' health beliefs. A number of theories or models have tried to summarize various factors and provide a theoretical foundation for adherence studies. Those models are usually adapted from theories developed to explain preventive health behaviors and use of health services and now they have been utilized to understand or predict patient adherence to medical regimens. The most common theory for explaining treatment adherence behaviors is the Health Belief Model. In this model, patients' beliefs regarding their disease, medications, and medication taking behaviors are mainly reflected in perceptions of disease severity and susceptibility, as well as perceived benefits and perceived barriers of treatment. Assessing patients' beliefs regarding HIV/AIDS and its treatment should provide insight on their adherence to HIV treatments.

Studies of treatment adherence among HIV patients to date have been limited. None to our knowledge has examined the relationship between health beliefs, treatment adherence, and disease severity. 


\title{
CHAPTER 3
}

\section{RATIONALE AND THEORETICAL FRAMEWORK}

\begin{abstract}
Rationale
Patients' experiences with a disease and its treatment are likely to influence their beliefs about the disease and the treatment regimen prescribed for them (Bandura, 1977; Rosenstock, 1966). Patients' beliefs, attitudes, and adherence behaviors may vary with their disease status and experiences. Anecdotal reports of clinicians and at least two studies suggest that patients' adherence to antiretroviral therapy varies over the course of the disease (Graham et al., 1994; Smith, 1996). Two possible explanations for this are changes in patients' health beliefs based upon their experience with the disease and its treatment as well as an increased treatment regimen complexity associated with increasing disease severity. Consequently, one might suspect that the relationship between the severity of a disease and mediction adherence is mediated by one's health beliefs, or simply mediated by an increased treatment regimen complexity, or both. However, no study has verified this proposed relationship between disease severity, health beliefs and treatment adherence.
\end{abstract}




\section{Theoretical Framework}

This study used the following framework to examine the associations between disease severity, health beliefs, and treatment adherence.

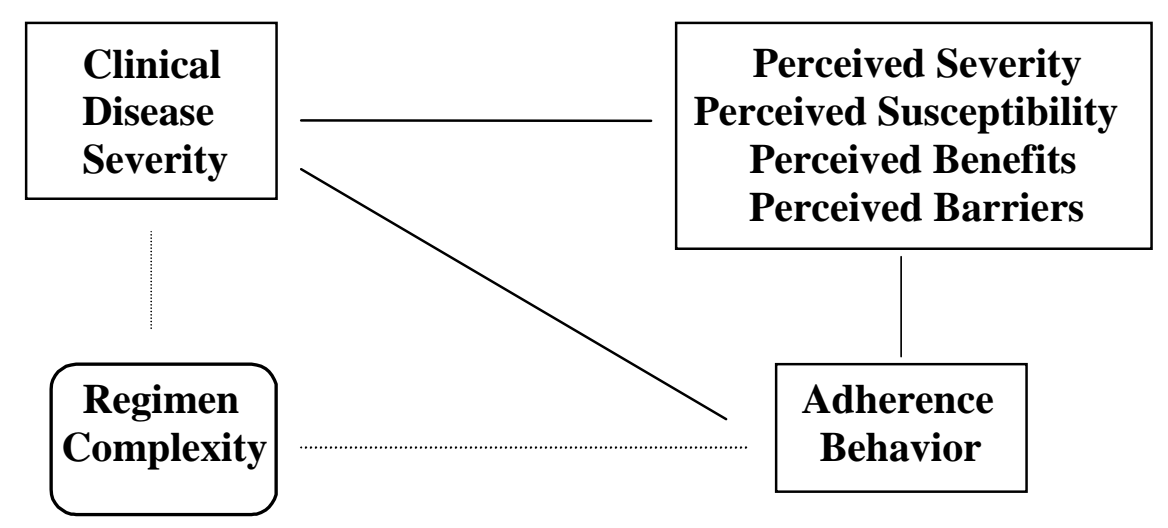

Figure 3-1. The framework for explaining the associations between disease severity, health beliefs, and treatment adherence.

Four beliefs are drawn from the health belief model (HBM) and the revised HBM: Perceived severity and perceived susceptibility are evaluated in a given condition. They are the perceived seriousness of the disease and the perceived chance of disease aggravation, made conditional on the alternative adherence or non-adherence to the treatment. Perceived benefits are what patients perceive they will derive from their treatment adherence behaviors. Perceived barriers are what patients perceive they will have to overcome to adhere to their antiretroviral therapy. Perceived barriers are explored as nonmonetary (e.g., inconvenience of treatment, side effects of drugs, interrupted social activities) and monetary (e.g., long-term health care costs, expenditures on drugs) (Rosenstock, 1966; Ronis, 1992; Nau, 1997). 


\section{Study Questions and Hypotheses}

Based on the review of the literature in this area, specific research questions and corresponding study hypotheses were formulated. Question 3, 4, 5, and 7 were exploratory questions, thus no hypotheses were proposed.

\section{Research Question 1:}

What is the relationship of disease severity and the perceived severity of AIDS related complications among HIV patients?

Hypothesis 1: The perceived severity of AIDS related complications among HIV patients will increase as disease severity increases.

\section{Research Question 2:}

What is the relationship of disease severity and the conditional perceived susceptibility of AIDS related complications among HIV patients?

Hypothesis 2: The perceived susceptibility-inaction will increase as disease severity increases and susceptibility-action among HIV patients will decrease as disease severity increases.

\section{Research Question 3:}

What is the relationship of disease severity and the perceived benefits of antiretroviral therapy held by HIV patients?

\section{Research Question 4:}

What is the relationship of disease severity and the perceived barriers coming from monetary costs of antiretroviral therapy among HIV patients?

\section{Research Question 5:}

What is the relationship of disease severity and the perceived barriers coming from non-monetary costs of antiretroviral therapy among HIV patients? 


\section{Research Question 6:}

What is the relationship of disease severity and treatment adherence behaviors of HIV patients?

Hypothesis 3: The adherence of antiretroviral therapy among HIV patients will increase as disease severity increases.

\section{Research Question 7:}

To what extent are health beliefs, regimen complexity, and demographic factors related to medication taking behaviors among HIV patients? 


\section{CHAPTER 4}

\section{METHODS}

This section presents the methods employed to achieve the research objectives. It includes study population, sampling methods, data collection, instrument development and validation, data analysis, and limitations.

\section{Study Population}

\section{$\underline{\text { Sample Selection }}$}

The primary sample was drawn from the infectious disease clinic at West Virginia University Hospital (WVUH), and the AIDS clinics at Charleston Area Medical Center (CAMC) and University of Maryland Hospital (UMH). About 60, 30, and 150 patients were available from WVUH, CAMC, and UMH respectively during the data collection period. Patients were eligible for this study if they met the following criteria:

- confirmed diagnosis of HIV infection;

- using antiretroviral therapy for at least one month;

- age 18 years or older;

- mentally competent.

\section{$\underline{\text { Sample Size }}$}

This study used multivariate analyses of variance (MANOVA) to determine whether four health beliefs differ across the three clinical categories (study objective 1 to 4). Hence, the clinical categories serve as 3 levels for the independent variable (clinical status) and the health beliefs serve as the dependent variables. Unfortunately, there is no simple equation for calculating sample size for MANOVA. Tabachnick and Fidell (1996) suggest that to appropriately perform a MANOVA, each cell of the MANOVA matrix must contain at least as many subjects as dependent variables and that robustness is enhanced when there are at least 20 subjects per level of the independent variable. If the expected response size is achieved $(n=100)$ with no less than $20 \%$ of subjects at any of the three levels of the independent variable, then the MANOVA should be adequately 
robust.

The extent to which medication adherence varies across clinical category (objective 5) was assessed with a one-way analysis of variance (ANOVA). Power analysis was used to estimate sample size. Power is defined as the "probability that a statistical test will yield statistically significant results" (Cohen, 1988). The sample size for a given study is a function of: (1) alpha, the probability of Type I error; (2) the power for the study; and (3) the effect size expected in the study (Cohen, 1988). For most social science research alpha is set at 0.05 and power is 0.80 . Effect size (d) is estimated from past research, pilot test data, expert opinion or rough estimates. As we have no estimate of effect size either from past literature or theory, Cohen (1988) provides rough estimates of effect size. To be able to detect a medium effect, say $d=0.5$, and power of $80 \%$ for a two-tailed test with alpha $=0.05$, the required sample size would be 64 (Table 2.4.1, pg 55, Cohen, 1988). Past studies, in which health beliefs and medication taking behaviors of HIV patients were examined, used between 40 and 113 subjects (Geletko, 1995; Morse, 1991; Samet, 1992; Muma, 1995). This is quite comparable to the estimated sample size of the current study.

A multiple regression model was used to investigate the influence of regimen complexity, demographic parameters, and health beliefs on medication-taking behaviors (objective 6), where medication adherence is the dependent variable. Under the same assumptions above (effect size $=0.5, \beta=0.2$, and $\alpha=0.05$ ), the required sample size would be 73 for testing multiple correlation and individual predictors (Green, 1991).

\section{Data Collection Procedures}

A cross-sectional study design was employed using self-administered surveys. Data were collected over a six-month period from May to December 1998 by using a convenience sample of patients visiting the AIDS clinics. The relatively long data collection period was partly due to the departure of a physician in the clinic of CAMC. Since there was only an interim MD in the clinic with a schedule of five patients per week, it took several months to survey the majority of patients.

Patients who met the inclusion criteria were informed by the physician, or the clinic pharmacist, about the purpose and nature of the study. Written information 
regarding the study and the patient's right to refusal were provided. A copy of the cover letter is provided in Appendix D. Patients who agreed to participate were given the written questionnaire on which their pharmacist or physician had indicated the patient's disease stage. The patients were classified as stage A, B, or C according to the CDC criteria (CDC, 1997). The disease category was selected based upon whether the patient had ever experienced the indicator conditions, rather than his/her current status (Appendix E). The subjects were allowed to complete the survey in the clinic or take it home. Patients were also provided with a stamped return envelope and asked to seal the survey within the envelope upon completion. The sealed envelopes were returned to investigators at the WVU School of Pharmacy for data analysis. Hence, the physician would not see the patient's responses and the investigators at the School of Pharmacy would not know the identity of the respondent thereby ensuring anonymity.

\section{Instrument Development and Validation}

\section{Item Construction}

Based on the literature review and expert panel (the clinical pharmacists and physicians in both WVUH and CAMC), items were developed to measure disease severity, health beliefs, regimen complexity, and medication-taking behaviors of HIV patients. Multi-item scales were developed for medication adherence and health beliefs. The questionnaire consists of five parts: questions about prescriptions and clinical conditions; treatment screening questions; health beliefs assessment questions, including assessment of perceived susceptibility, severity, benefits, and barriers; medication-taking behavior assessment questions; and demographic questions.

Study variables are (1) disease severity, (2) regimen complexity, (3) perceived susceptibility - inaction, (4) perceived susceptibility - action, (5) perceived severity inaction, (6) perceived severity - action, (7) perceived severity - comparative; (8) perceived benefits, (9) perceived barriers, (10) perceived value, (11) medication adherence, and (12) demographic variables.

The variable definitions are presented in the following sections. The final version of the research instrument is presented in Appendix F. 


\section{Disease Severity}

In this study, disease severity was included as an independent variable. Clinic personnel indicated the patient's disease category as $\mathrm{A}, \mathrm{B}$, or $\mathrm{C}$ according to $\mathrm{CDC}$ criteria. The disease category was selected based upon whether the patient had ever experienced the indicator conditions, rather than his/her current status. Stage A is defined as asymptomatic, acute (primary) HIV or persistent generalized lymphadenopathy (PGL); Stage B is defined as symptomatic conditions not included in stage A and stage C; Stage C is defined by AIDS-indicator conditions such as Kaposi's sarcoma (Appendix A \& B).

\section{$\underline{\text { Regimen Complexity }}$}

The complexity or burden of a medication regimen is a function of the number of doses per day as well as special requirements regarding the use of the medication (such as take on an empty stomach). Currently, there is no consensus on the ideal way to assess medication regimen complexity. This study used the number of weekly doses as an indicator of regimen complexity. From the first item of the questionnaire, the regimen complexity score was calculated for each patient as the sum of weekly doses for all medications taken regularly. The dosage for the medications prescribed for use "as needed" (i.e., PRN) were not included unless the patient indicated that they took these medications frequently and regularly.

\section{Perceived Susceptibility - Inaction}

This variable reflects the degree to which an individual feels threatened by aggravation of HIV infection when not adhering to his/her medication regimen. The perception was measured on a five-point scale from 1 "very low" to 5 "very high" and was found in the questionnaire as item 10. High susceptibility given inaction is associated with higher probability of taking the action (adhering to the medication regimen) (Ronis, 1992).

\section{Perceived Susceptibility - Action}

This variable reflects the degree to which an individual feels threatened by aggravation of HIV infection when he/she adheres to the prescription. This perception was measured on a five-point scale from 1 "very low" to 5 "very high" and was found in the questionnaire as item 11. High susceptibility given action is associated with lower 
probability of taking the action (Ronis, 1992).

Perceived Severity - Inaction

This variable shows the patients' perception of the severity of AIDS or AIDS related complications (ARC) when they do not adhere to their prescription. It was measured at item 13 on a five-point likert scale (defined at the poles by the words "strongly disagree" and "strongly agree"). High perceived severity given inaction is associated with higher probability of taking the action (Ronis, 1992).

Perceived Severity - Action

This variable shows the patients' perception of the severity of AIDS or ARC when they adhere to their prescription. It was measured at item 14 on a five-point Likert scale (defined at the poles by the words "strongly disagree" and "strongly agree"). High severity given action is associated with lower possibility of taking the action (Ronis, 1992).

\section{Perceived Severity - Comparative}

This variable measures patients' perception of severity of HIV/AIDS compared to other diseases. This construct is not contingent on patients' medication taking behaviors.

\section{$\underline{\text { Perceived Benefits }}$}

This variable reflects the degree to which patients perceive that they can benefit from their medication adherence behaviors. This scale consisted of three items pertaining to the benefits of adherence behaviors (prolonging life and reducing health threat, item 15 and 18) and the perceived efficacy of the medications (item 22). A five-point Likert scale anchored by "strongly disagree" and "strongly agree" was used.

\section{$\underline{\text { Perceived Barriers }}$}

This variable is defined as perceived non-monetary barriers and monetary barriers to adherence behavior. Non-monetary barriers included interrupted social activities, side effects of drugs, psychological barriers for the treatment, medication effectiveness, and difficult instructions. These appeared in the questionnaire as items 16, 19, 20\&21, 23, and 24 respectively. Perceived monetary barrier was measured by item 17. A five-point Likert scale anchored by "strongly disagree" and "strongly agree" was used.

\section{$\underline{\text { Perceived Value }}$}

This variable reflects the extent to which the respondent believes that adhering to 
the treatment is worthwhile. Conceptually, it represents the net utility of an action based upon a tradeoff of benefits and costs (Zeithaml, 1988) and may be more closely related to behavior intent than any other health belief (Nau, 1997). In this study, perceived value was measured by asking subjects' overall evaluation of their medications and medicationtaking behaviors. A five-point Likert scale (defined at the poles by the words "strongly disagree" to "strongly agree", and "negative" to "positive") was used . It can be found as questionnaire item 25 and 26.

\section{Medication Adherence}

The variables of medication adherence were measured by a four-item self-report scale (Morisky, et al., 1986) and by self-reports of missed doses (Samet, et al., 1992). The 4-item self-reported scale developed by Morisky was adapted in this study as adherence measure1: (1) Do you ever forget to take your medicine? (2) Are you careless at times about taking your medicine? (3) When you feel better do you sometimes stop taking your medicine? (4) Sometimes if you feel worse when you take the medicine, do you stop taking it? The second question "Are you careless at times about taking your medicine?" in the Morisky scale was reworded to "Are you always careful about taking your medications?" because patients may feel uncomfortable about the word "careless". Adherence was defined as an ordinal variable ranging from 0 - 4 with higher scores indicating greater adherence. Morisky et al. (1986) also suggest that a score of 4 indicates "high" adherence, 2 or 3 indicate "medium" adherence, and 0 or 1 indicate a "low" adherence level.

The second and third measures of medication adherence operationally defined adherence as the percentage of doses taken as prescribed during a specified time interval. They were measured as a continuous variable and calculated by the following formula [(prescribed doses - missed doses) $\div$ (prescribed doses)] (Samet, et al. 1992). The question used by Samet and colleagues to determine the number of missed doses focused only on medication use during the last 24 hours. While this limited time frame may enhance the accuracy of patient recall, it may not be reflective of the overall trend in the patient's medication adherence. Hence, patients were asked to indicate the number of missed doses during the past two days and during the past two weeks. Responses to the two items were compared to determine the congruency of responses. Subsequent 
analyses were conducted using the adherence rate calculated from both approaches. Given the exploratory nature of this study, it was appropriate to investigate the extent to which different measures of adherence may produce different results. This has important implications for future research in this area.

In order to compare three adherence measures, measure 2 and measure 3 were further categorized into three levels - high, medium, and low. However, there was no standard cutoff value for each level in literature, especially in HIV/AIDS studies. In a Meta analysis conducted by Tseng (1998) and a study conducted by Samet (1992), adherence was defined as taking $>80 \%$ of doses as prescribed. Broers et al. (1994) defined adherence in a cohort study of drug users' compliance with Zidovudine treatment as good, moderate, or bad when, respectively, $80 \%$ or more, $50 \%$ to $79 \%$, or less than $50 \%$ of prescribed treatment was taken. However, they did not mention the time interval when they measured adherence rates. Also, although their conclusion was that compliance of drug users was no worse than the compliance of patients from other risk groups, it is still not reliable to generalize these cutoff values to this study. Based on the knowledge on this issue, HIV medication adherence for this study was defined as high, medium, and low when, respectively, $91 \%$ to $100 \%, 81 \%$ to $90 \%$, and less than $81 \%$ of prescribed medications was taken during the past two days or during the past two weeks.

The agreement of three adherence measures was evaluated by Kappa statistics. Kappa measures the agreement between two raters when both are rating the same object. The difference between the observed proportion of cases in which the raters agree and the proportion expected by chance is divided by the maximum difference possible between the observed and expected proportions, given the marginal totals (Cohen, 1960; Landis and Koch, 1977; Fleiss, 1981). A value of 1 indicates perfect agreement. A value of 0 indicates that agreement is no better than chance.

\section{Demographic Variables}

The following demographic variables were measured: age, gender, ethnicity, education level, and income. Prior research has shown these variables to be influential on health beliefs. In addition, they served as a means of assuring that the characteristics of the respondents were consistent with the general clinic population. 


\section{Content Validity}

The clarity and face validity of the survey instrument was assessed prior to its distribution. The face validity of the instrument used in this study was assessed via expert review. Experts in health services research from the Department of Pharmaceutical Systems \& Policy, and clinicians from the HIV/AIDS clinics of WVUH and CAMC reviewed the instrument to determine its clarity and appropriateness. Based upon the expert review, a revision made to the questionnaire was the addition of the item 33: “Have you purposefully chosen to discontinue any of your HIV medications?". A list of possible reasons for medication discontinuations and an open question about the reasons were also added. This item identifies the patients who choose not to adhere to their medications. Minor changes were made in question wording and ordering. The final instrument is shown in Appendix F.

\section{Construct Validity}

A factor analysis was conducted to determine whether the item responses "clustered" together consistent with the operational definitions of specified constructs or subscales. The Health Belief Model (HBM) subscales (perceptions of susceptibility, severity, benefit, and costs) were verified with principal axis factor analysis followed by varimax rotation among HBM items (item 10 -24). The correlations of items within and between subscales were also examined. For a valid measurement scale, the correlations within subscales should be higher than the correlations of items between subscales (Nunnally, 1978).

\section{Reliability}

Reliability is a statistical measure of the reproducibility of the survey instrument's data. While there are several types of reliability such as stability, equivalence, inter- and intra-rater reliability, internal consistency (homogeneity) is particularly important for multi-item scales (Litwin, 1995). In this study, the internal consistency of each multiitem scale (perceived benefits, perceived barriers, and adherence measure1) was confirmed by calculating coefficient alpha and item-to-total correlations. Coefficient alpha is the average of all the correlations between each item and the total score and 
estimates how consistent subjects performed across items measuring the same construct (Streiner \& Norman, 1995). According to Cohen (1988), high values of the coefficient alpha indicate a consistent performance. An alpha of greater than 0.60 is generally considered acceptable (Robinson et al., 1991). In addition, item-to-total correlation statistics were used to identify problematic items in each of the instrument dimensions. They are especially relevant when there are few items in a scale (Ferketich, 1991). Bearden et al. (1985) considered 0.50 as an acceptable value of a corrected item-to-total correlation to maintain an item. However, Nunnally (1978) suggests that corrected itemto-total correlations above 0.30 may be sufficient. SPSS software also provides coefficient alpha if the item is deleted for each item. If there is a substantial improvement in alpha when the item is deleted, then it may be considered problematic and deleted to enhance the consistency of instrument scales. However, scale alpha if item deleted is not the only excluding criteria. Decisions regarding the deletion of the item should be based upon conceptual as well as statistical considerations. Coefficient alpha, item-to-total correlations, and scale alpha if item deleted were calculated for each multiitem scale (perceived barriers, perceived benefits, and adherence measure1).

\section{Data Analysis}

Statistical Package for Social Sciences (SPSS - 7.5) was used for data analysis. The data file contained seventy-two cases that represented the usable questionnaires. The data file was meticulously checked to correct errors from data entry. Frequencies were then obtained for all study variables to double check and clean data.

The following analytical methods were used to accomplish each of the study objectives.

Disease Severity (DS) Health Beliefs (HB)
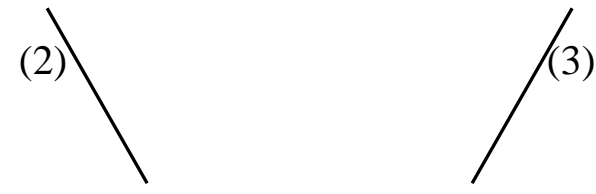

Medication Adherence (MA) 
(1) MANOVA

(2) ANOVA

(3) Multiple Regression

\section{Analytical Methods for Objective 1-4}

Multivariate analysis of variance (MANOVA) was utilized to investigate the effects of disease severity on health beliefs. MANOVA is a generalization of one-way analysis of variance (ANOVA) to a situation in which there are several dependent variables (DVs). It tests whether mean differences among groups on a combination of DVs are likely to have occurred by chance (Tabachnick and Fidell, 1996). In this study, the influences of disease severity on several health beliefs (perceived severity and susceptibility of the disease, perceived barriers and benefits of the treatement) were examined. Therefore, the independent variable was disease severity with three levels $(\mathrm{A}, \mathrm{B}, \mathrm{C})$. The health beliefs served as dependent variables. By measuring several health beliefs at the same time instead of measuring only one of them, the effect of interactions between these beliefs will be taken into account and inflated type I error due to multiple tests of correlated beliefs will be avoided.

Stepdown analysis was used as a post hoc analysis for significant multivariate effects since there are more than two levels in the multivariate main effect. Specific comparisons among three levels of disease severity pointed out the source of the significant difference in each health belief.

Analytical Methods for Objective 5

Analysis of variance (ANOVA) was used to compare two or more mean scores to determine if there are any statistically significant differences among them. In this study, the extent to which medication adherence varies across clinical category was assessed with a one-way ANOVA. Since regimen complexity may affect medication adherence and increase with disease severity, regimen complexity was used as a covariate in this analysis. By doing so, the linear effect of regimen complexity upon the dependent variable (medication adherence) is removed separately from the effect of the factor categories (disease severity). Therefore, the main effect of disease severity was assessed after adherence scores were adjusted for differences associated with regimen complexity. This may increase the sensitivity of the test of main effect by reducing the interaction 
between medication adherence and regimen complexity.

Analytical Methods for Objective 6

A multiple regression model was used to investigate the influence of regimen complexity, health beliefs, and demographic factors on medication taking behaviors. Stepwise method was used for regression analysis in order to understand the relative influence of each independent variable on medication adherence.

\section{Limitations of the Study}

Theoretical Issues

Measurement of regimen complexity. As mentioned before, there is currently no consensus on the ideal way to assess medication regimen complexity. The complexity or burden of a medication regimen is a function of the number of doses per day as well as special requirements regarding the use of the medication (such as "take on an empty stomach"). However, the literature is devoid of any reliable and valid means of calculating the burden of special requirements. This study used the number of weekly doses for all relevant prescribed medications as an indicator of regimen complexity. The limitations of this simple measure of regimen complexity are obvious (e.g., the measurement ignored the special requirements along with the use of medications and only reflected a maximized regimen weekly dosage instead of accurately reflecting the regimen complexity). In addition, since the main objectives of this study were to investigate the relationship of disease severity and health beliefs, this simple measure may be a reasonable way to estimate regimen complexity in this preliminary study.

Measurement of medication adherence. Adherence to the prescribed medications for HIV/AIDS was measured by a four-item self-reported scale (Morisky, et al, 1986), and by self-reports of missed doses (Samet, et al. 1992). Patient self-administered questionnaires were used to obtain a patient's subjective evaluation of his or her medication adherence behaviors. It may have induced some error due to recall bias and social desirability. However, by comparing the results obtained from multiple measures, a rough estimate of the accuracy or at least consistency or these measures can be made.

The other two measures of adherence used in this study can only reflect the missing doses. Incorrect dosage intervals can not be detected by these measures. 
Definitions and measurements of health beliefs. Perceived susceptibility inaction, perceived susceptibility - action, perceived severity - inaction, perceived severity - action, perceived benefits, perceived barriers, and perceived value were defined and measured as health beliefs in this study. It is very difficult to distinguish perceived severity - inaction and perceived severity - action for a serious disease such as HIV infection. Furthermore, the items used to measure each perception may not perfectly represent the constructs in theory. While a factor analysis was conducted to verify the operational definition of each subset of items, a strong relationship among a set of items may be due to strong influence of one item (or some items) over another instead of their representing the same construct.

Causality. The statistical analyses used in this study (MANOVA, ANOVA, and multiple regression) revealed the relationship between disease severity, health beliefs, and medication adherence. However, they did not imply that the relationships were causal.

\section{$\underline{\text { Practice Issues }}$}

Sample size. The number of subjects was quite small in this study. Most patients were in stage A. Some patients in stage B or C were too sick to complete the survey. To avoid this problem, later studies may use a larger sample pool for patients in stage B and C.

Influence of study settings. This study was conducted in clinical sites. The clinical pharmacist, social worker, or physicians introduced and distributed the survey to patients. Thus some patients may feel predisposed to give more desirable responses (such as a higher adherence rate and positive value to the treatment) despite being informed that their individual responses would not be shared with the clinicians. 


\section{CHAPTER 5}

\section{RESULTS}

\section{Subjects}

Seventy-two patients completed the survey, representing $30.0 \%$ of the 240 patients who had scheduled clinic appointments during the six months data collection period. According to the experience of clinic pharmacists, the majority of nonrespondents either forgot to complete or send the survey, or were too sick to complete the survey.

Demographic characteristics of the sample are shown in Table 5-1. Most patients were white $(52.9 \%)$ male $(73.1 \%)$, with an age between 25 and 44 years old (78.0\%). About forty-three percent of respondents had college or graduate education and $70.6 \%$ of respondents earned less than 20,000 a year. Regarding the type of insurance coverage, Medicaid was the major payer for the patients surveyed (42.9\%), followed by private insurance companies (22.1\%) and the Ryan White Consortium (14.3\%). Only three patients $(3.9 \%)$ reported that they had to pay for HIV medications mainly by themselves.

Clinical characteristics of the sample are presented in Table 5-2. The distribution of patients categorized in each disease stage was not equal. Most patients were in the first (asymptomatic) and third (AIDS/ARC) stage (44.5\% and 34.7\%, respectively), compared to $20.8 \%$ of patients in stage two (HIV-symptomatic). There are about equal numbers of patients in asymptomatic (A) stage and symptomatic (B and C) stage (44.5\% and $55.5 \%$, respectively). More than half of the patients $(59.1 \%)$ reported taking 3 to 5 medications, and $19.8 \%$ of the patients reported taking even more $(>=6)$ medications. In addition, more than half $(59.2 \%)$ of the respondents visited their physician once every 2 3 months or every 4 - 5 months, and only $2.8 \%$ of the patients visited their physician

more than once a month. Nearly all respondents (97.2\%) indicated that they had been taking medications for HIV/AIDS for more than four months.

Patients were also asked to indicate their current and lowest CD4+ counts, as well 
as current and highest viral load. Five patients (7.2\%) did not know their current CD4+ counts, 9 patients (13.0\%) did not know their lowest CD4+ counts, 17 patients (25.0\%) did not know their recent viral load, and 23 patients (33.8\%) did not know their highest viral load ever. 
Table 5-1. Demographic Characteristics of Respondents $(N=72)$

\begin{tabular}{llcc}
\hline & CHARACTERISTIC & FREQUENCY & PERCENT ( \%) \\
\hline Gender & & 49 & 73.1 \\
\cline { 2 - 3 } & Male & 18 & 26.9 \\
& Female & & \\
Age & & 1 & 1.5 \\
& $18-24$ years & 21 & 30.9 \\
& $25-34$ years & 32 & 47.1 \\
& $35-44$ years & 14 & 20.5
\end{tabular}

Ethnicity

White

Black or African-American

Other
36

31

1

52.9

45.6

1.5

Education

Less than 9th grade

2

9th to 12th grade

Some college, no degree

Bachelors degree

8

11.8

Graduate or professional degree

6

8.8

Income

Less than $\$ 10,000$

45.6

10,000 - 19,999

17

25.0

20,000 - 29,999

6

8.8

$30,000-49,999$

11

50,000 or more

3

16.2

4.4

Type of Major Insurance

Medicaid

Private Insurance

Ryan White Consortium

Drug Company

$3 \quad 3.9$

Self-Pay

3

3.9

Other

12.9 
Table 5-2. Clinical Characteristics of Respondents $(N=72)$

CHARACTERISTIC FREQUENCY PERCENT ( \%)

Disease Category

$\begin{array}{lll}\text { A } & 32 & 44.5 \\ \text { B } & 15 & 20.8 \\ \text { C } & 25 & 34.7\end{array}$

Number of Medications

Less than 3

3

4

5

6

More than 6

Visit Frequency

More than once a month

Once a month

Once every 2 - 3 months

Once every 4 - 5 months

Once every half a year or longer
15

14

12

16

6

8

2

24

35

7

3

2

6

62
21.1

19.7

16.9

22.5

8.6

11.2

2.8

33.8

49.3

9.9

4.2

Duration of Therapy

2 - 3 months

4 - 6 months

More than 6 months
2.8
62.6

8.6

88.6 


\section{Study Variables}

\section{Disease Severity}

Clinic personnel indicated the patient's disease category as A, B, or C on the questionnaire. The results were reported in Table 5-2.

\section{Perceived Severity - Inaction}

This variable showed the patients' perception of the severity of AIDS or AIDS related complications (ARC) when they did not adhere to their prescription regimen. The mean and standard deviation of the perception score were 4.13 and 0.97 , respectively (Table 5-3a). A mean score above four with a small standard deviation suggested that most patients perceived they would become very sick if they did not take their medications as prescribed.

\section{$\underline{\text { Perceived Severity - Action }}$}

This variable showed the patients' perception of the severity of AIDS or AIDS related complications (ARC) when they adhered to their prescription regimen. The mean and standard deviation of the perception score were 2.52 and 1.04, respectively (Table 53a). Although $54.9 \%$ of the patients disagreed or strongly disagreed with the statement, some patients $(29.6 \%)$ were neutral regarding their becoming very sick even if they took their medications as prescribed. 
Table 5-3a. Study Variables - Health Beliefs

\begin{tabular}{|c|c|c|c|c|c|c|}
\hline Variables and Items & $\begin{array}{c}\text { Strongly } \\
\text { Disagree } \\
(\%)\end{array}$ & $\begin{array}{l}\text { Disagree } \\
(\%)\end{array}$ & $\begin{array}{l}\text { Neutral } \\
\quad(\%)\end{array}$ & $\begin{array}{l}\text { Agree } \\
(\%)\end{array}$ & $\begin{array}{c}\text { Strong } \\
\text { Agree } \\
(\%)\end{array}$ & Mean \pm Std.Dev. * \\
\hline \multicolumn{7}{|l|}{ Perceived Severity - Inaction: } \\
\hline $\begin{array}{l}\text { I'll become very sick if I'm not adherent } \\
\text { Perceived Severity - Action: }\end{array}$ & 1.4 & 7.0 & 11.3 & 38.0 & 42.3 & $4.13 \pm 0.97$ \\
\hline I'll become very sick if I'm adherent & 14.1 & 40.8 & 29.6 & 9.9 & 5.6 & $2.52 \pm 1.04$ \\
\hline \multicolumn{7}{|l|}{ Perceived Severity - Comparative } \\
\hline Compared to other illnesses, HIV/AIDS is very serious & 5.6 & 4.2 & 7.0 & 26.8 & 56.4 & $4.28 \pm 1.11$ \\
\hline \multicolumn{7}{|l|}{ Perceived Benefits: } \\
\hline Adherence can prolong my life & 2.8 & 0.0 & 5.6 & 39.4 & 52.1 & $4.38 \pm 0.83$ \\
\hline Adherence can decrease the chances of getting worse & 5.6 & 4.2 & 21.1 & 31.0 & 38.0 & $3.92 \pm 1.13$ \\
\hline HIV medications I'm taking can improve my health & 2.8 & 0.0 & 19.7 & 42.3 & 35.2 & $4.07 \pm 0.90$ \\
\hline \multicolumn{7}{|l|}{ Perceived Barriers: } \\
\hline Interfering a great deal with my normal activities & 21.1 & 36.6 & 15.5 & 14.1 & 12.7 & $2.61 \pm 1.32$ \\
\hline Making me feel more nervous or depressed than usual & 12.6 & 26.8 & 22.5 & 26.8 & 11.3 & $2.97 \pm 1.23$ \\
\hline Causing annoying side effects & 5.7 & 12.9 & 18.6 & 40.0 & 22.8 & $3.61 \pm 1.15$ \\
\hline Dealing with the side effects is stressful & 10.0 & 14.3 & 20.0 & 44.3 & 11.4 & $3.33 \pm 1.16$ \\
\hline More effective if I take medications. only when I feel bad & 53.5 & 35.2 & 4.2 & 1.4 & 5.6 & $1.70 \pm 1.03$ \\
\hline Difficult to follow doctors' instructions on medications & 36.6 & 36.6 & 12.7 & 5.6 & 8.5 & $2.13 \pm 1.22$ \\
\hline HIV medications are too expensive for me & 12.9 & 17.1 & 10.0 & 28.6 & 31.4 & $3.49 \pm 1.42$ \\
\hline \multicolumn{7}{|l|}{ Perceived Value: } \\
\hline Taking HIV medications is worth the hassle & 4.2 & 4.2 & 8.5 & 36.6 & 46.5 & $4.17 \pm 1.04$ \\
\hline
\end{tabular}


Table 5-3a. (CONTD.) Study Variables - Health Beliefs

\begin{tabular}{|c|c|c|c|c|c|c|}
\hline Variables and Items & $\begin{array}{l}\text { Negative } \\
(\%)\end{array}$ & $\begin{array}{c}\text { Somewhat } \\
\text { Negative } \\
(\%)\end{array}$ & $\begin{array}{l}\text { Neutral } \\
(\%)\end{array}$ & $\begin{array}{c}\text { Somewhat } \\
\text { Positive } \\
(\%)\end{array}$ & $\begin{array}{l}\text { Positive } \\
(\%)\end{array}$ & Mean \pm Std.Dev. * \\
\hline \multicolumn{7}{|l|}{ Perceived Value: } \\
\hline 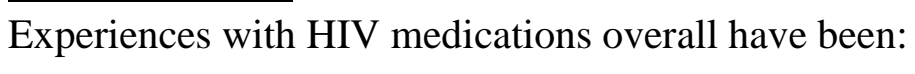 & 2.9 & 1.4 & 7.2 & 29.0 & 59.4 & $4.41 \pm 0.91$ \\
\hline Variables and Items & $\begin{array}{c}\text { Very } \\
\text { Low } \\
(\%) \\
\end{array}$ & $\begin{array}{c}\text { Low } \\
(\%)\end{array}$ & $\begin{array}{c}\text { Intermediate } \\
(\%)\end{array}$ & $\begin{array}{l}\text { High } \\
(\%)\end{array}$ & $\begin{array}{c}\text { Very } \\
\text { High } \\
(\%)\end{array}$ & Mean \pm Std.Dev. * \\
\hline$\frac{\text { Perceived Susceptibility - Inaction: }}{\text { Chances of getting worse if not adherent }}$ & 3.1 & 1.6 & 21.9 & 34.3 & 39.1 & $4.05 \pm 0.98$ \\
\hline $\begin{array}{l}\text { Perceived Susceptibility - Action: } \\
\text { Chances of getting worse if adherent }\end{array}$ & 30.4 & 33.3 & 26.1 & 7.2 & 2.9 & $2.19 \pm 1.05$ \\
\hline
\end{tabular}

* For all subscales, higher scores represent greater amounts of the construct. 


\section{Perceived Severity - Comparative}

This item asked patients how severe they thought HIV/AIDS was compared to other illness. Most patients $(83.2 \%)$ disagreed or strongly disagreed with the statement "Compared to other illness, HIV/AIDS is NOT very serious" (Table 5-3a).

\section{$\underline{\text { Perceived Benefits }}$}

The perceived benefits were operationally defined as the degree to which patients perceive that they can benefit from their medication adherence behaviors. It was comprised of three items, each of which was measured on a five-point Likert scale (Table 5-3a). For all three items, the means were higher than the midpoint, especially for the item "Taking medications as prescribed can prolong my life" (mean = 4.38, S.D. = 0.83). This suggests that most patients believed adhering to their medications was beneficial.

\section{$\underline{\text { Perceived Barriers }}$}

The perceived barriers were defined as both non-monetary and monetary barriers to adherence behavior. The non-monetary barriers were measured by five items and the perceived monetary barrier was measured by one item (Table 5-3a). The majority of patients agreed or strongly agreed that HIV medications caused annoying side effects, that dealing with the side effects was stressful, and HIV medications were very expensive. Also, the vast majority of the patients disagreed or strongly disagreed with the statements "HIV medications will work more effectively if I take them only when I am feeling bad" and "It is difficult to follow doctors' instructions on HIV medications". However, there was considerable variation in perceptions about "Taking HIV medications or having side effects from them makes me feel more nervous or depressed than usual" $($ mean $=2.97$, S.D. $=1.23)$ and "Taking HIV medications interferes a great deal with my normal activities" (mean $=2.61$, S.D. $=1.32)$.

\section{$\underline{\text { Perceived Value }}$}

Perceived value was defined as the extent to which the patient believed that adhering to his/her treatment was worthwhile. For the item that stated "Taking my HIV medications is worth the hassle", the responses were scored on a five-point agreement scale. The mean and standard deviation of the perceived value score were 4.17 and 1.04, respectively (Table 5-3a). Another variable measuring perceived value stated as "Overall, would you say your experiences with HIV medications have been__" The 
responses were scored on a five-point scale with 1 representing "negative" and 5 representing "positive". The mean and standard deviation of the perceived value score were 4.41 and 0.91 , respectively (Table 5-3a). The mean scores of both items were close to 5, which indicates that most patients believe that taking their medications is worthwhile.

\section{$\underline{\text { Perceived Susceptibility - Inaction }}$}

This variable measured the degree to which a patient felt threatened by aggravation of HIV infection (i.e. developing AIDS-related complications) when not adhering to his/her medication regimen. Most patients $(73.4 \%)$ rated their chances of getting worse "high" or "very high" if they did not take HIV medications as prescribed. The mean and standard deviation of the perception scores were 4.05 and 0.98 , respectively, on a five-point scale (Table 5-3a). The mean was relatively high, which suggests that patients generally perceive the probability of getting worse is high if they do not adhere to their medication regimens.

Perceived Susceptibility - Action

This variable measured the degree to which a patient felt threatened by aggravation of HIV infection (i.e. developing AIDS-related complications) when taking his/her medication regimen as prescribed. Nearly two-thirds $(63.7 \%)$ of the patients rated their chances of getting worse as low or very low if they take HIV medications as prescribed. The mean and standard deviation of the perception score were 2.19 and 1.05, respectively (Table 5-3a). A mean below the midpoint of the scale suggests that patients generally perceive the probability of getting worse is low if they adhere to their medication regimens.

\section{$\underline{\text { Regimen Complexity }}$}

The number of weekly doses was calculated as an indicator of regimen complexity. The number of weekly doses ranged from 14 to 147 with a mean and standard deviation of 54.94 and 24.26, respectively (Table 5-3b). Thus, patients took about eight doses a day on average. 
Table 5-3b. Study Variables - Regimen Complexity and Medication Adherence

\begin{tabular}{ccc}
\hline Variables & Range & Mean \pm Std. Dev.* \\
\hline Regimen Complexity & $14-147$ & $54.94 \pm 24.26$ \\
Adherence Measure1 & $1-4$ & $2.90 \pm 0.93$ \\
Adherence Measure2 & $0 \%-100 \%$ & $93.10 \pm 15.20$ \\
Adherence Measure3 & $0 \%-100 \%$ & $96.39 \pm 12.82$ \\
\hline
\end{tabular}

* For all scales, higher scores represent greater amounts of the construct. 


\section{Medication Adherence}

Measure1. Medication adherence was first measured by a four-item scale with higher scores indicating greater adherence. The score was based upon the number of "No" responses (recoded for \#2) and reflected the degree to which a patient adhered to his/her medications. More than one third of the patients $(35.2 \%)$ reported that they did not ever forget to take their medicine; $83.1 \%$ patients said they were always careful about taking their medicine; $87.3 \%$ patients would not stop taking their medicine when they feel better; and $84.5 \%$ patients would not stop taking their medications even if they feel worse when they take the medicine. The mean and standard deviation of the scale were 2.90 and 0.93 (Table 5-3b).

Measure1 was developed by Morisky et al. (1986). They suggest that a score of 4 indicates "high" adherence, 2 or 3 indicate "medium" adherence, and 0 or 1 indicate a "low" adherence level. In this study, $28.2 \%$ of the patients were categorized as high adherence, $62.0 \%$ as medium adherence and only $9.8 \%$ as low adherence.

Measure $2 \&$ Measure3. The second and third measure of medication adherence defined adherence as the percentage of doses taken as prescribed during a specified time interval. The average missed doses during the past two days and the past two weeks were 0.8 and 2.3, respectively. According to the formula [(prescribed doses - missed doses) $\div$ (prescribed doses)] * 100\% (Samet, et al. 1992), the medication adherence score ranged from $0 \%$ to $100 \%$ with a mean of $93.1 \%$ during the past two days and ranged from $0 \%$ to $100 \%$ with a mean of $96.4 \%$ during the past two weeks (Table 5-3b).

In order to compare the three adherence measures, measure 2 and measure 3 were further categorized into three levels - high, medium, and low. Based on our knowledge on this issue, we defined HIV medication adherence as high, medium, and low when, respectively, $91 \%$ to $100 \%, 81 \%$ to $90 \%$, and less than $81 \%$ of prescribed medications was taken during the past two days or during the past two weeks.

Agreement of three measures. The conformity of the three adherence measures was evaluated by Kappa statistics (Table 5-4). Kappa measures the agreement between two raters when both are rating the same object. A value of 1 indicates perfect agreement. A value of 0 indicates that agreement is no better than chance. Results showed that measure1 and measure3 had lowest agreement $($ Kappa $=0.03, p=0.34)$. 
Measure1 and measure 2 were also incompatible (Kappa $=0.07, p=0.24)$. However, the agreement between measure 2 and measure 3 was statistically significant albeit not ideal $($ Kappa $=0.26, p<0.001)$.

Intentional discontinuation of the medications. Patients were also asked whether they had purposefully chosen to discontinue any of their HIV medications and why. Most of them (79.4\%) reported they have never purposefully stopped taking their HIV medications. For those who had discontinued their HIV medications on purpose, intolerable side effect was the most common reason (100\%). Additional reasons included "they are expensive" (14\%), "taking them is complicated and inconvenient for me" (14\%), "refilling prescriptions or regular clinic check is a burden on me" (7\%), and "I heard/observed worsening of HIV symptoms in others taking their medications" (14\%). 
Table 5-4. Agreement of Three Measures for Medication Adherence

\begin{tabular}{ccccc}
\hline & Kappa & $\begin{array}{c}\text { Asymp. } \\
\text { Std.Error }^{\mathrm{a}}\end{array}$ & $\mathrm{T}^{\mathrm{b}}$ & $p$ \\
\hline Measure1-Measure2 & 0.07 & 0.06 & 1.18 & 0.24 \\
Measure1-Measure3 & 0.03 & 0.03 & 0.96 & 0.34 \\
Measure2-Measure3 & 0.26 & 0.12 & 4.18 & $<0.001^{*}$ \\
\hline
\end{tabular}

a. Not assuming the null hypothesis.

b. Using the asymptotic standard error assuming the null hypothesis.

$*$ Kappa is significantly different from zero when alpha $=0.05$. 


\section{Construct Validity}

Construct validity of health beliefs was assessed by conducting a principal component analysis followed by varimax rotation. Five dimensions of health beliefs were extracted and accounted for $71.3 \%$ of variance in beliefs about HIV medications and adherence behaviors (Table 5-5). These dimensions measured: perceived nonmonetary barriers of taking HIV medications as prescribed; perceived benefits of HIV medications or adherence behaviors; perceived monetary cost of HIV medications; concepts related to risks of non-adherence; and perceived comparative severity of HIV/AIDS. The variance accounted for by these five factors were $24.4 \%, 15.3 \%, 12.6 \%$, $9.7 \%$, and $9.3 \%$, respectively.

The factor analysis suggests that the patients' perceptions of monetary barriers and non-monetary barriers were conceptually distinct. It also reveals that several items clustered because of their relationship to either the benefits of adherence or the risks of non-adherence. The items measuring perceived susceptibility-action and perceived susceptibility-inaction were under the dimensions of adherence benefits and nonadherence risks, respectively. This may be due to the wording of the questions. Unlike what was expected, item 23 "HIV medications will work more effectively if I take them only when I am feeling bad" and item 24 "It is difficult to follow doctors' instructions on HIV medications" had low factor loadings (-0.06 and 0.28 , respectively), which means

they do not reflect well the concept of barriers as defined in this study. Similarly, item 22 "The HIV medications that I'm taking will improve my health" was also separate from other items measuring treatment benefits (factor loading $=0.15$ ). 
Table 5-5. Factor Structure of Beliefs about HIV/AIDS and the Treatment

Factors and Items*

Loading

Factor 1 - Perceived Barriers (non-monetary)

Item

21. Dealing with the side effects is stressful

20. Medications make me feel more nervous or depressed $\quad 0.87$

19. Medications cause annoying side effects $\quad 0.86$

16. Medications interfer a great deal with my normal activities $\quad 0.67$

[ $24.38 \%$ of variance, Eigenvalue $=3.17$ ]

Factor 2 - Benefits of Adherence

Item

15. Adherence can prolong my life $\quad 0.78$

18. Adherence can decrease the chances of getting worse 0.77

11. Chances of getting worse if adherent $\quad-0.71$

[ $15.27 \%$ of variance, Eigenvalue $=1.99$ ]

Factor 3 - Monetary Barriers

17. HIV medications are too expensive for me $\quad 0.73$

[ $12.55 \%$ of variance, Eigenvalue $=1.63$ ]

Factor 4 - Risks of Non-Adherence

Item

10. Chances of getting worse if not adherent 0.84

23. More effective if I take meds. only when I feel bad $\quad-0.61$

[ $9.71 \%$ of variance, Eigenvalue $=1.26$ ]

Factor 4 - Perceived Comparative Severity

Item

12r. Compared to other illnesses, HIV/AIDS is very serious 0.82

[ $9.35 \%$ of variance, Eigenvalue $=1.22$ ]

* Only loading scores above 0.60 (absolute value) are reported. 


\section{Scale Reliability}

Multi-item scales were used to measure health beliefs (perceived benefits and perceived barriers) and treatment adherence measure1. Given that the study is exploratory, an alpha estimate of 0.60 and above was considered reasonable in this study. Scale statistics and reliability coefficients for multi-item scales are presented in Table 5-6 and 5-7. The Perceived Benefits scale included three items. The item "HIV medications I'm taking can improve my health" had a low item-total correlation (0.19). Also, the Alpha could be increased from 0.52 to 0.62 if the item was deleted. Therefore, this item was excluded from the scale of perceived benefits. The final Alpha, or Pearson correlation coefficient, for this two-item scale was 0.62. The Perceived Barriers scale only included non-monetary barriers since the factor analysis suggested the perceived monetary cost and non-monetary barriers should be separated as two different components. Item-total correlations for the item "HIV medications will work more

effectively if I take them only when I am feeling bad" and "it is difficult to follow doctors' instructions" were very low (0.02 and 0.24 , respectively). It indicated that these items were different from other items measuring barriers. Thus, they were deleted from the scale. The final Chronbach's alpha was 0.85 , which was relatively high.

In contrast to the results of a prior study (Morisky et al., 1986), Adherence Measure1 had very low reliability $(\alpha=0.38)$. The item-total correlations for the four items were also very low. It indicated that this measure may not be an ideal measure of adherence. 
Table 5-6. Item-Total Correlation and Corrected Alpha

\begin{tabular}{|c|c|c|}
\hline Item & $\begin{array}{l}\text { Item - Total } \\
\text { Correlation }\end{array}$ & $\begin{array}{c}\text { Alpha If } \\
\text { Item Deleted }\end{array}$ \\
\hline \multicolumn{3}{|l|}{ Perceived Benefits } \\
\hline Adherence can prolong my life & 0.42 & 0.31 \\
\hline Adherence can decrease the chances of getting worse & 0.43 & 0.24 \\
\hline HIV medications I'm taking can improve my health & 0.19 & $0.62^{*}$ \\
\hline \multicolumn{3}{|l|}{ Perceived Barriers (non-monetary) } \\
\hline Dealing with the side effects is stressful & 0.70 & 0.60 \\
\hline Making me feeling more nervous or depressed than usual & 0.69 & 0.59 \\
\hline Causing annoying side effects & 0.59 & 0.63 \\
\hline Interfering a great deal with my normal activities & 0.52 & 0.65 \\
\hline Difficult to follow doctors' instructions on HIV medications & 0.24 & $0.78^{*}$ \\
\hline More effectively if I take them only when I am feeling bad & 0.02 & $0.74^{*}$ \\
\hline \multicolumn{3}{|l|}{ Medication Adherence Measure1 } \\
\hline Do you ever forget to take any of your meds. & 0.28 & 0.21 \\
\hline Are you always careful about taking your meds. & -0.01 & 0.51 \\
\hline When you feel better do you sometimes stop taking your meds. & 0.29 & 0.23 \\
\hline $\begin{array}{l}\text { Sometimes if you feel worse when you take the medication, } \\
\text { do you stop taking it? }\end{array}$ & 0.29 & 0.22 \\
\hline
\end{tabular}

* Item deleted from the final scale. 
Table 5-7. Scale Statistics and Reliability Coefficients

\begin{tabular}{lccc}
\hline \multicolumn{1}{c}{ Multi-item scales } & Number of Items & $\begin{array}{c}\text { Scale } \\
\text { Mean } \pm \text { S.D. }\end{array}$ & Alpha \\
\hline Perceived Benefits & 2 & $8.30 \pm 1.69$ & 0.62 \\
Perceived Non-monetary Barriers & 4 & $12.65 \pm 3.99$ & 0.85 \\
Medication Adherence1 & 4 & $2.90 \pm 0.93$ & 0.38 \\
\end{tabular}




\section{Objective A to D Results}

The first objective of the study was to compare the perceived severity of AIDS related complications among HIV patients in different disease stages. It was hypothesized that the perceived severity of AIDS related complications held by HIV patients would increase as disease severity increased. The second objective of the study was to compare the perceived susceptibility to AIDS related complications held by HIV patients in different disease stages. It was hypothesized that conditional perceived susceptibility of AIDS related complications held by HIV patients would increase as disease severity increased. The third objective of the study was to compare the perceived benefits of antiretroviral therapy held by HIV patients in different disease stages. The fourth objective of the study was to compare the perceived barriers to medication adherence held by HIV patients in different disease stages. The monetary and nonmonetary barriers were examined separately.

MANOVA was conducted to achieve these four objectives. The mean and standard deviations of health beliefs across three disease severity categories are presented in Table 5-8. Using $\alpha=0.05$, the multivariate tests did not show significant effects of disease severity on patients' health beliefs (Wilks' $\lambda=0.76, p=0.21$ ). More specifically, there was no statistically significant difference in patients' perceived severity of HIV/AIDS and perceptions of benefits and barriers of the treatment across three disease stages. However, tests of between-subjects effects revealed that disease severity did influence patients' perception of susceptibility-inaction $(F=3.38, p=0.04)$. Further Post Hoc tests (LSD method) showed there were significant differences in perceived susceptibility-inaction between patients in stage $\mathrm{A}$ and $\mathrm{C}(p=0.01)$. That means patients who have greater experience with the disease are more likely to consider themselves at risk for complications if they don't take their medicine. 
Table 5-8. Health Beliefs among Patients in Different Disease Stages*

\begin{tabular}{|c|c|c|c|c|c|}
\hline Health Beliefs & $\begin{array}{l}\text { Stage } \mathrm{A} \\
\mathrm{M} \pm \mathrm{SD}\end{array}$ & $\begin{array}{l}\text { Stage B } \\
\mathrm{M} \pm \mathrm{SD}\end{array}$ & $\begin{array}{l}\text { Stage C } \\
\mathrm{M} \pm \mathrm{SD}\end{array}$ & $F$ & $p$ \\
\hline Perceived Severity & $4.41 \pm 0.84$ & $3.79 \pm 1.58$ & $4.55 \pm 0.83$ & 2.39 & 0.10 \\
\hline Susceptibility - action & $2.19 \pm 1.00$ & $1.79 \pm 0.89$ & $2.25 \pm 0.97$ & 1.08 & 0.35 \\
\hline Susceptibility - inaction & $3.78 \pm 0.89$ & $4.07 \pm 0.83$ & $4.45 \pm 0.89$ & 3.38 & $0.04^{* *}$ \\
\hline Perceived Benefits & $8.30 \pm 1.61$ & $8.50 \pm 1.34$ & $8.15 \pm 2.13$ & 0.17 & 0.85 \\
\hline Perceived Non-monetary Barriers & $13.78 \pm 3.95$ & $11.29 \pm 4.20$ & $12.65 \pm 3.92$ & 1.83 & 0.17 \\
\hline Perceived Monetary Barriers & $3.56 \pm 1.40$ & $3.36 \pm 1.34$ & $3.55 \pm 1.61$ & 0.10 & 0.91 \\
\hline
\end{tabular}

* For all subscales, higher scores represent greater amounts of the construct.

** The mean difference is significant at $\alpha=0.05$. 


\section{Objective E Results}

The fifth objective of the study was to examine medication adherence of HIV patients with antiretroviral therapy in different disease stages. It was hypothesized that the adherence of antiretroviral therapy among HIV patients would increase as disease severity increased.

Means and Standard Deviations of medication adherence across three disease stages are shown in Table 5-9. It revealed that the mean level of medication adherence did increase as disease severity increased across all adherence measures.

Simple factorial ANOVA was used to assess the significance of the effects of disease severity on patients' medication adherence. In addition, regimen complexity was included in the analysis as a covariate to control for its influence on adherence (Table 510). The dependent variable was based on the adherence score obtained by adherence

measure2 (missed doses in past two days). Adherence measure2 was utilized in the analysis because the following reasons: 
Table 5-9. Medication Adherence among Patients in Different Disease Stages

\begin{tabular}{|c|c|c|c|}
\hline Medication Adherence & $\begin{array}{l}\text { Stage A } \\
\mathrm{M} \pm \mathrm{SD}\end{array}$ & $\begin{array}{l}\text { Stage B } \\
\mathrm{M} \pm \mathrm{SD}\end{array}$ & $\begin{array}{l}\text { Stage C } \\
\mathrm{M} \pm \mathrm{SD}\end{array}$ \\
\hline Measure1 & $2.74 \pm 0.82$ & $3.08 \pm 0.86$ & $3.13 \pm 0.97$ \\
\hline Measure2 & $90.29 \pm 12.82$ & $96.83 \pm 6.30$ & $98.84 \pm 3.20$ \\
\hline Measure3 & $96.41 \pm 6.10$ & $98.42+2.76$ & $99.32 \pm 1.12$ \\
\hline
\end{tabular}


Table 5-10. Effects of Disease Severity on Medication Adherence

\begin{tabular}{|c|c|c|c|c|}
\hline \multirow[t]{2}{*}{ Adherence (Measure2) } & \multicolumn{2}{|c|}{ Disease stage A,B,C } & \multicolumn{2}{|c|}{ Asymptomatic v.s. Symptomatic } \\
\hline & $F$ & $p^{*}$ & $F$ & $p^{*}$ \\
\hline Main Effects: Disease Severity & 3.85 & 0.026 & 7.72 & 0.007 \\
\hline Covariate: Regimen Complexity & 3.80 & 0.046 & 4.17 & 0.045 \\
\hline Model & 5.43 & 0.002 & 8.22 & 0.001 \\
\hline
\end{tabular}

* All effects are significant at $p=0.05$. 
1) Only Measure2 had significant correlations with the health beliefs and highest $R^{2}$ $\left(p=.006, R^{2}=.48\right)$;

2) Measure2 had significant agreement with measure3;

3) Measure 1 had a very low reliability coefficient $(\alpha=0.38)$ in this study.

The unique or main effect of disease severity on medication adherence was significant among three disease stages $(F=3.85, p=0.03)$. However, the mean adherence score for stages $\mathrm{B}$ and $\mathrm{C}$ were very close (Table 5-9). Thus, we combined those patients in stages $\mathrm{B}$ and $\mathrm{C}$ (symptomatic) and compared this symptomatic group to the asymptomatic patients in stage A. This resulted in a more dramatic difference in adherence scores $(F=7.72, p=0.007)$. Consequently, patients with some experience of HIV/AIDS complications were more adherent to their medications compared to patients who had never experienced complications.

\section{Objective F Results}

The final objective of this study was to investigate the influence of regimen complexity and health beliefs on patients' self-reported medication adherence. In addition, the effects of demographic characteristics on patients' adherence were examined. 
Table 5-11. The Relationship between Medication Adherence and Health Beliefs, Regimen Complexity, and Demographic Factors

\begin{tabular}{lccc}
\hline \multicolumn{1}{c}{ Variables } & Beta & $t$ & $p$ \\
\hline & & & \\
Included Variables & & & \\
\hline Susceptibility-inaction & 0.36 & 2.92 & 0.005 \\
Difficulty in following doctors' & -0.33 & -2.69 & 0.009 \\
instructions & & & \\
& & & \\
Excluded Variables & & & \\
Non-monetary Barriers & -0.19 & -1.52 & 0.14 \\
Susceptibility-action & -0.16 & -1.28 & 0.21 \\
Perceived Severity & 0.10 & 0.77 & 0.44 \\
Perceived Benefits & 0.04 & 0.00 & 0.99 \\
Monetary Barriers & -0.19 & -1.48 & 0.15 \\
Regimen Complexity & 0.06 & 0.44 & 0.66 \\
Age & -0.01 & -0.09 & 0.93 \\
Gender & 0.07 & 0.53 & 0.60 \\
Race & -0.02 & -0.17 & 0.96 \\
Education & 0.11 & 0.86 & 0.39 \\
Income & 0.04 & 0.34 & 0.73 \\
Improving my health & -0.09 & -0.69 & 0.50 \\
More effective when I feel bad & 0.09 & 0.71 & 0.48 \\
& & & \\
\hline
\end{tabular}

* Using $p=0.05$ as entry criteria in stepping method.

$*$ Regression Model: $F=8.00, p=0.001$. 
A multiple regression analysis using a stepwise method was conducted to achieve objective F. Individual health beliefs were entered into the regression model in addition to summated scale scores. Results are presented in Table 5-11. Two significant predictors of patients' medication adherence were detected. Perceived susceptibilityinaction was positively associated with their adherence $(\beta=0.36, t=2.92, p<0.01)$. The higher perceived chance of getting worse if not taking their medications as prescribed, the more likely that patients would be adherent. Medication adherence was also negatively related to the difficulty of following doctor's instructions on HIV medications $(\beta=-0.33$, $t=-2.69, p<0.01)$. The more difficult to follow doctors' instructions felt by the patient, the less he/she was adherent to the treatment.

Other health beliefs such as scales of perceived barriers and benefits, perceived susceptibility-action, and perceived severity did not significantly affect medication adherence. In addition, results of the regression analysis showed that regimen complexity alone was not a significant predictor of patients' medication adherence. Finally, no demographic factors such as age, gender, race, education, and income were found to relate to medication adherence. The final regression model thus included two predictors: perceived susceptibility-inaction and difficulty in following doctors' instructions on HIV medications $(F=8.00, p<0.01)$.

\section{Influence of Ethnicity on Health Beliefs}

The primary sample was drawn from three sites: the infectious disease clinic at West Virginia University Hospital (WVUH), and the AIDS clinics at Charleston Area Medical Center (CAMC) and University of Maryland Hospital (UMH). There were substantial differences between patients from West Virginia and Maryland. Table 5-12 shows an overall comparison of the three sites on demographic and clinical characteristics of patients. There was no statistically significant difference between the three sites on age, income, gender, disease severity, medication numbers, regimen complexity, and on-therapy time. However, race, education level, and visit frequency were significantly different between the three sites $(p<0.05)$. The respondents from WVUH and CAMC were predominately white and male, whereas the respondents from UMH were predominately African-American and included many females (Table 5-13). 
The sample was consistent with the study population of each clinic in race and gender distribution as estimated by clinic staff.

In order to obtain a better understanding of the influence of ethnicity on health beliefs and medication adherence, white patients and African-American patients were compared in their health beliefs, medication taking behaviors, and awareness of disease. Table 5-14 shows there was no statistically significant difference between white and black patients in most health beliefs about HIV/AIDS and its treatment except for perceived severity, perceived interference with normal activities, and reserving medications for bad conditions. Compared to white patients, African-American patients perceived HIV/AIDS to be less serious; perceived that taking medications interfered less with normal activities; were less stressed by medication side effects; and were less likely to disagree that medications "work more effectively if I take them only when I am feeling bad". The African-American respondents were also less likely to perceive medications as being too expensive.

It is important to note that nearly all of the African-American respondents were at UMH. Hence, the racial differences in responses could actually be due to other characteristics of the site (e.g., the process of care). 
Table 5-12. Comparison of Three Sites on Demographic and Clinical Characteristics

Characteristics

Demographics

Age

Gender

Race

Education

Income

Clinical Characteristics

Disease Severity

Number of Medications

Regimen Complexity

Visit Frequency

On-therapy Time
Test Statistics

$X^{2}=5.46$

0.49

$X^{2}=5.61$

0.06

$X^{2}=56.55$

$<0.0001^{*}$

$X^{2}=18.90$

$0.02^{*}$

$X^{2}=12.23$

0.14

$X^{2}=7.02$

0.13

$F=0.28$

0.76

$F=0.50$

0.61

$X^{2}=18.57$

$0.02^{*}$

$X^{2}=7.73$

0.26 
Table 5-13. Patients' Composition of Three Sites by Gender and Race

\begin{tabular}{cccccccc}
\hline & \multicolumn{2}{c}{ WVUH } & \multicolumn{2}{c}{ CAMC } & \multicolumn{2}{c}{ UMH } \\
Race & Male & Female & Male & Female & Male & Female & Total \\
\hline White & 18 & 3 & 11 & 3 & 1 & 0 & 36 \\
African-American & 1 & 0 & 1 & 0 & 15 & 12 & 29 \\
Other & 0 & 0 & 0 & 0 & 1 & 0 & 1 \\
Total & 19 & 3 & 12 & 3 & 17 & 12 & 66 \\
\end{tabular}


Table 5-14. Medication Adherence and Health Beliefs by Race

\begin{tabular}{|c|c|c|c|c|}
\hline & $\begin{array}{c}\text { White } \\
\text { M } \pm \text { S.E. }\end{array}$ & $\begin{array}{c}\text { African-American } \\
\qquad \pm \text { S.E. }\end{array}$ & $F$ & $p$ \\
\hline Medication Adherence (Measure2) & $96.65 \pm 0.97$ & $90.47 \pm 3.89$ & 2.89 & 0.09 \\
\hline Susceptibility - inaction & $4.18 \pm 0.16$ & $3.88 \pm 0.19$ & 1.58 & 0.21 \\
\hline Susceptibility - action & $2.24 \pm 0.16$ & $1.88 \pm 0.19$ & 2.12 & 0.15 \\
\hline Perceived Severity & $4.64 \pm 0.18$ & $3.79 \pm 0.21$ & 9.47 & $.003^{*}$ \\
\hline \multicolumn{5}{|l|}{ Perceived Benefits } \\
\hline - prolonging life & $4.39 \pm 0.16$ & $4.29 \pm 0.18$ & 0.18 & 0.68 \\
\hline - preventing getting worse & $4.15 \pm 0.18$ & $3.71 \pm 0.22$ & 2.45 & 0.12 \\
\hline - improving health ${ }^{* *}$ & $4.06 \pm 0.16$ & $3.88 \pm 0.19$ & 0.54 & 0.46 \\
\hline \multicolumn{5}{|l|}{ Perceived Non-monetary Barriers } \\
\hline - interfering activities & $3.00 \pm 0.22$ & $2.21 \pm 0.26$ & 5.32 & $0.03^{*}$ \\
\hline - causing annoying side effects & $3.91 \pm 0.19$ & $3.50 \pm 0.22$ & 2.03 & 0.16 \\
\hline - making me feel nervous/depressed & $3.27 \pm 0.21$ & $3.00 \pm 0.25$ & 0.69 & 0.41 \\
\hline - making me feel stressful & $3.76 \pm 0.19$ & $3.07 \pm 0.22$ & 4.21 & 0.05 \\
\hline - difficult to understand instructions ${ }^{* *}$ & $2.09 \pm 0.22$ & $2.33 \pm 0.26$ & 0.51 & 0.48 \\
\hline - taking them only when I feel bad ${ }^{* *}$ & $1.49 \pm 0.19$ & $2.08 \pm 0.22$ & 4.27 & $0.04^{*}$ \\
\hline Perceived Monetary Barriers & $3.85 \pm 0.24$ & $3.08 \pm 0.29$ & 4.14 & 0.05 \\
\hline
\end{tabular}

* For all subscales, higher scores represent greater amounts of the construct.

** Items deleted from the final "Benefit" or "Barriers" scale. 
Due to the fact that the influence of disease severity on health beliefs may be biased by race, MANOVA was conducted to examine whether there was an interaction of disease severity and race. By using disease severity and race as two independent factors, the individual effects and their interactions can be detected. Results showed that there was no interaction between disease severity and race (Wilks' $\lambda=0.72, p=0.20$ ) and further confirmed the reports in Table 5-8 and Table 5-14: disease severity alone had no significant influence on patients' health beliefs except for susceptibility-inaction and African-American patients had significantly lower perceived severity of HIV/AIDS and lower perceived treatment barriers related to side effects, interference with normal activities and monetary cost.

Although white patients had a higher mean score of medication adherence than black patients, the difference was not significant $(p=0.09)$. In other word, race had no significant relationship with medication adherence in this study. Regarding the awareness of disease, 17\% of African-American patients didn't know their current CD4+ counts, whereas all white patients reported their current CD4+ count; $24 \%$ of AfricanAmerican patients didn't know their lowest CD4+ counts ever, compared to 5\% of white patients; $45 \%$ African-American patients didn't know their recent viral load, compared to $11 \%$ of white patients; and finally, $48 \%$ African-American patients didn't know their highest viral load ever, compared to $23 \%$ of white patients. 


\section{CHAPTER 6}

\section{DISCUSSIONS AND RECOMENDATIONS}

This chapter presents a review of this study and discusses its major findings. Where applicable, conclusions are drawn regarding those findings. In addition, the implications of this study are stated and recommendations for future research are made.

\section{Study Review}

The advent of highly active antiretroviral therapy (HAART) means that more HIV patients need to take multiple medications for longer periods (Tseng, 1998). In addition, many antiretrovirals may have adverse effects, rigorous dosage and administration requirements, be associated with numerous drug interactions, and be very expensive (Deeks et al., 1997; Swindells and Gendelman, 1996). Medication adherence among HIV patients becomes a very serious issue. However, there is limited research addressing this issue, especially a lack of theory-based studies regarding medication use among patients with HAART. In addition, since symptoms can vary greatly in frequency and severity among HIV patients (Centers for Disease Control, 1997; Tseng, 1998), there is likely to be considerable variability amongst HIV patients' perceptions of disease severity and progression as well as perceived benefits and costs of treatment. Patients' medication adherence may also be influenced by their disease experiences. However, very little is known about how disease severity affects patients' beliefs about disease and medications and patients' medication taking behaviors.

The goal of this study was to investigate the relationship of disease severity, health beliefs and medication taking behaviors among HIV/AIDS patients. The health belief model (HBM) was used to build the theoretical framework for this study. Consistent with the work of Ronis (1992) and Nau (1997), the perceived susceptibility was measured as "conditional" based upon the subjects' behavior. Additionally, the 
perceived barriers component was measured as non-monetary (e.g., inconvenience of treatment, side effects of drugs, interrupted social activities) and monetary components (e.g., expenditures on drugs).

The association between disease severity, health beliefs and medication adherence was examined using a combination of clinician reported and patient self-reported data. Furthermore, this study enrolled patients in all three CDC categories for HIV/AIDS and addressed patients' adherence to the entire drug regimen rather than just one drug as in many studies (Geletko et al., 1995; Muma et al., 1995; Samet et al., 1992; Broers et al., 1994; etc.).

\section{Discussion of Results}

\section{Health Beliefs of HIV Patients}

Four health beliefs were drawn from the HBM: perceived susceptibility and severity of the disease, and perceived benefits and barriers of the treatment. The factor analysis suggested that patients' perceptions of susceptibility-inaction and susceptibilityaction were different from each other, but related to similarly worded questions about the risks of non-adherence and benefits of adherence (Table 5-5). This leads to a possible explanation that the degree to which a patient feels threatened by aggravation of HIV infection is conditional upon whether or not they take their medications. Perceived susceptibility may be highly correlated with the perceived effectiveness (i.e., perceived benefit) of the treatment. For example, a patient who believes that his medications are highly effective is more likely to believe that he is at lower risk of complications as long as he takes his medications as prescribed, and that he is at higher risk if he does not take his medications as prescribed.

The relative severity of the disease was measured by the statement "Compared to other illness, HIV/AIDS is very serious". There was little variability among the responses of patients as $83.2 \%$ of those agreed HIV/AIDS was very serious (Mean = 4.28). This result is comparable to the findings of other compliance studies among HIV patients (Muma, 1995; Geletko, 1995; Morse, 1991). It illustrates that for a severe disease like HIV/AIDS, it is difficult and may not be appropriate to measure 
"conditional" perceived severity.

Another finding from the factor analysis on health beliefs was that the perceived monetary barriers and non-monetary barriers were shown conceptually distinct. This is consistent with some prior studies on HBM (Ronis, 1992; Nau, 1997). However, many compliance studies using the HBM construct did not delineate between these two constructs (e.g., Muma, 1995; Geletko, 1995; Morse, 1991).

Finally, the factor analysis and test of internal consistency showed that the perceived ability of HIV medications to improve overall health did not fit the scale of perceived benefits (low factor loading and item-to-total correlation). Perhaps most patients feel HIV medications are more effective in stabilizing their disease conditions than for improving their overall health.

\section{$\underline{\text { Relationship of Disease Severity and Health Beliefs }}$}

There was no relationship between the stage of HIV/AIDS and perceptions of benefits or barriers of the treatment, or perceived comparative severity of the disease (Table 5-8). It is reasonable that the actual seriousness of disease did not affect patients' perceived severity since the majority of patients felt that HIV/AIDS was serious. In addition, most patients agreed their treatment was very beneficial regardless of their disease stage. This may be due to the fact that treatments for HIV/AIDS have developed remarkably in recent years. Compared to treatments in the 1980's and the early 1990's, the new combined antiretroviral therapy has significant improvement in treatment effectiveness. The progress is so obvious that most patients appreciate the new technologies/medicines for prolonging their life and preventing disease aggravation (See Appendix G: "Patients' Comments"). It is reasonable that patients' perceived benefits of the treatment are quite uniform and not influenced by their actual disease severity.

On the other hand, despite the development in HIV/AIDS medications, side effects of antiretrovirals are still relatively common and difficult to avoid due to the limited numbers and classes of antiretrovirals. All antiretroviral agents are associated with considerable toxicities (Carpenter et al., 1996). Also, the combined antiretroviral therapy increases regimen complexity, which may be more inconvenient for patients. Patients without severe disease-related symptoms may perceive high treatment barriers because the side effects of their medications appear relatively intolerable compared to 
their disease experience whereas patients with advanced disease may perceive high treatment barriers because they actually experience a greater incidence of adverse effects. As the course of HIV disease progresses and treatment alternatives become limited, it is more likely that remaining treatment options will have overlapping adverse effect profiles (Carpenter et al., 1996). However, patients with AIDS or ARC may also perceive the side effects of medications and/or other inconveniences caused by the treatment more tolerable compared to the advancement of their disease. Although the responses to individual barrier items were mixed, the summated barriers scale indicated that the overall perception of barriers was relatively high (Table 5-3a).

The means of perceived cost among patients in all three disease stages were around 3.5 which was above the midpoint, but not very high (Table 5-8). Perceived monetary cost may be associated with both out-of-pocket price and perceived disease severity. Therefore, it is understandable that disease severity did not significantly affect patients' perception of monetary cost since most patients felt HIV/AIDS was a serious disease and more than seventy percent of the patients have insurance (e.g., Medicaid, Ryan White Consortium, or other private or state insurance programs) (Table 5-1).

Disease severity was associated with perceived susceptibility-inaction. That means HIV patients who have had severe complications perceive themselves to be at greater risk of getting worse when not adherent as compared to patients who have never experienced complications. On the contrary, there was no significant difference in perceived susceptibility-action among HIV patients in different disease stages. This further verified the conclusion of Ronis (1992) that susceptibility-inaction and susceptibility-action should be evaluated separately. The measure of susceptibilityinaction may be more sensitive to the symptoms patients experienced than that of susceptibility-action.

\section{Medication Adherence among HIV Patients}

Three measures were used in this study to assess medication adherence. Measure1 was developed by Morisky and colleagues (1986). The second and third measures defined adherence as the percentage of doses taken as prescribed during the past two days and the past two weeks, respectively. Results showed that these three measures were poorly compatible with each other (Table 5-4). The agreement between measure 2 and 
measure3 was statistically significant (Kappa $=0.3, p<0.01)$, but not substantial. No agreement was shown between measure 1 and the other two measures.

Measure1 appeared to be less promising as a measure of adherence when compared to measure 2 and measure3. In contrast to the results of a prior study (Morisky et al., 1986), measure1 had very low internal consistency $(\alpha=0.39)$. The item-total correlations for the four items were also very low (Table 5-7). This indicated that the measure might not be ideal for this study.

Compared to measure1, measure2 and measure 3 are more straightforward. Although measure 3 may be more reflective of the overall trend in the patient's adherence behaviors, it may be vulnerable to a recall bias. In addition, measure 2 showed more consistent correlations with the health beliefs examined. Therefore, measure2 (in which adherence was measured over the past two days) may be more suitable for this study. In many past studies, adherence was measured by the percentage of doses taken as prescribed during the past month (Muma, 1995), past week (Samet, 1992, Morse, 1991), and/or the past 24 hours (Samet, 1992). Using $80 \%$ as the adherence cutoff value, the reported rates of adherence have ranged from $40 \%$ to $71 \%$ (Tseng, 1998; Samet, 1992; Remien, 1998).

Inconsistent with the literature, self-reported medication adherence was quite high in our study patients: $66.2 \%$ had perfect adherence during the past two days, $89.7 \%$ had greater than $80 \%$ compliance, and only $4.4 \%$ missed more than $50 \%$ of their doses. The high adherence rate may be due to a selection bias among patients who didn't participate in the study. Compared to the patients who were willing to complete the survey and send it back, non-respondents may have lower adherence, with a resultant overestimation of compliance (Eraker et al., 1984; Feinstein, 1979; Morse, 1991). Also, it is conceivable that patients may be more adherent during the two days prior to an appointment. Thus the adherence rate may not be representative of the general population of persons with HIV.

Results also revealed that some patients $(21.2 \%)$ purposefully stopped taking their HIV medications and the most common reason for intentional non-adherence was the intolerable side effects of the medication.

$\underline{\text { Relationship of Disease Severity and Medication Adherence }}$ 
Medication adherence increased as patients' disease severity increased when regimen complexity was controlled. The trend was more significant between asymptomatic patients (stage A) and symptomatic patients (stage B and C) $(F=7.72, p=$ 0.007). Although one might expect less adherence in patients with more advanced HIV disease because of their increased medication needs and decreased level of physical functioning, this is often not the case. Patients who have experienced more disease symptoms are likely to have higher medication adherence. They may feel a higher risk of complications or have more experience in coping with the barriers of the treatment (e.g., side effects) compared to patients in the early stages of the disease.

Relationship of Health Beliefs, Regimen Complexity and Demographic Factors with Medication Adherence

Based on the results of a multiple regression analysis, we conclude that patients are more likely to take their medications as prescribed if they have higher perceived susceptibility-inaction and/or less difficulty in understanding doctors' instructions. These findings are consistent with the literature (Rosenstock, 1966; Ronis, 1992; Tseng, 1998). However, all other health beliefs were not significantly associated with adherence. Thus, they may not be the best predictors of medication adherence behaviors of HIV patients. It is understandable that the perceived severity of the disease (comparative), which the HBM holds as a predictor of adherence behavior, is not significant in this study due to uniformly high perceptions of perceived severity. This supports opinions of Rimer (1990) and Nau (1997) that the concept of perceived severity in HBM may have low utility when applied to severe illnesses.

Regimen complexity was found not a significant predictor of medication adherence. However, many studies have indicated that medication adherence is strongly associated with regimen complexity (Rudd, 1993; Eraker et al., 1984; Eldred et al, 1997; etc.). The lack of association in this study may be due to the fact that more than $75 \%$ of the patients took at least five doses a day and there was minimal variation in regimen complexity. It may also be due to limitations in the measure of regimen complexity. In this study, regimen complexity was calculated based on the number of daily doses. Complexity may actually be influenced by other issues such as the timing of the doses. For example, having to take five medications that are all taken at the same dosing interval 
(e.g., three times a day) may be easier than taking one medication twice daily, along with another medication dosed three times a day and a third drug dosed four times a day.

Finally, all demographic characteristics of the patients (age, race, gender, income, education) were not significant predictors of adherence. Literature regarding the influence of ethnicity on adherence is inconsistent. A study conducted by Muma et al. (1995) showed that African-American patients had a lower level of compliance (independent of education). Some other studies did not find ethnicity associated with non-adherence (Eldred et al., 1997; Besch et al., 1997; Morse et al., 1991). In this study, there was no significant difference in medication adherence between white patients and African-American patients.

\section{Causal Links}

Although there is no way to draw a definitive conclusion about the causality between disease severity, health beliefs (e.g., susceptibility-inaction), and medication adherence in this study, it is logical that patients' current medication adherence is influenced by their past disease experiences. It is possible that the effect of disease severity on medication adherence is mediated by patients' perceived risk of getting worse given non-adherence (susceptibility-inaction). Greater experience in dealing with disease symptoms and medication use can lead to a higher perceived risk of complications. The perceived link between non-adherence and the development of complications may be reinforced through one's personal or vicarious experience of having developed complications when non-adherent. Counseling by health professionals on the dangers of non-adherence may also influence this perception. The extant literature on the Health Belief Model suggests that a higher perceived susceptibility should translate into increased adherence behaviors. Conversely, patients who are in better health or who have had no symptoms may have poor medication adherence because they feel less immediately susceptible to the complications of the illness (low perceived susceptibilityinaction).

\section{Recommendations for Future Research}

This study is one of the first steps in the exploration of the relationship between disease severity, health beliefs, and medication adherence among HIV patients. It is not 
clear whether the effect of disease severity on medication adherence is mediated by patients' health beliefs such as perception of susceptibility-inaction. Path-analyses are needed to verify the theoretical model used in this study.

The relationship of disease severity, susceptibility-inaction, and medication adherence found in this study should also be tested in other disease states, especially in some chronic diseases with varied symptoms such as hypertension and heart disease. The implication of the need to conceptualize and measure conditional perceived disease severity and susceptibility should also be addressed in these future studies.

Many factors other than disease severity influence patients' health beliefs. Ethnicity is one of them. Additionally, ethnicity may affect medication adherence. Although this study examined the impact of ethnicity on health beliefs and medication adherence, it is not clear whether the apparent relationship of ethnicity and medication adherence is caused by site-related factors, patients' characteristics (e.g., education, drug use status, etc.), or mediated by patients' health beliefs such as perceived disease severity. Further research is needed to provide deep insight into the relationship between ethnicity, health beliefs, and medication adherence.

This study used the number of weekly doses as an indicator of regimen complexity. In addition, three different measures of medication adherence were used and compared. It is hoped that future research will develop more valid and reliable measurements of regimen complexity and medication adherence.

Finally, non-respondent patients may be more likely to have poor medication adherence, negative health beliefs, and/or unfavorable socioeconomic conditions. Issues regarding ways to increase response rate and to target non-respondents need to be addressed in further research.

\section{Implications of the Study Results}

HIV/AIDS is often viewed as a chronic, fatal illness that is managed with multiple drug therapies. Thus, patients' ability to manage their medications or long-term adherence to treatment becomes a critical issue. Medication adherence is recognized as an important factor determining the success of antiretroviral therapy. In order to develop and promote self-management of disease in HIV patients, partnership between the patient and the 
health care provider is required.

By understanding patients' medication taking behaviors and addressing adherence-related issues from patients' perspectives, health care providers can play an important role in helping establish optimal adherence in HIV patients. This requires that health care providers invest time educating patients about their disease and its treatment. As shown in this study, patients' medication taking behaviors are influenced by their disease severity and this influence may be mediated by patients' perceived risk of developing complications if they fail to adherent to their medication regimen. The importance of treatment adherence and the risks of non-adherence should be emphasized to all patients, especially for asymptomatic patients. Effective counseling should inform patients that non-adherence may cause disease aggravation and the failure of drug therapy which will limit future antiretroviral options because of cross-resistance. This is not to scare patients but to help them understand the potential negative consequences of poor adherence and encourage them to accept part of the responsibility for their treatment outcomes.

The results of this study also suggest that difficulty in following physicians' instructions is a significant barrier of medication adherence. This indicates that patients' medication adherence can be improved by enhancing the relationship and communications between patients and health care providers. Patients should always be encouraged to ask questions and be certain that they understand the instructions about their medications. It is also important for health care providers to share information about new therapies, discuss the disease and treatment, and keep patients aware of their disease. These may seem difficult for clinics with heavy work flow, but they are critical to decrease medication misuse and non-adherence and effective in reducing revisits in the long run.

The complexity of drug therapy for persons with HIV/AIDS presents an opportunity for pharmacists to play a greater role in enhancing drug-related outcomes. Difficulty in following doctors' instructions was found to be negatively related to patients' medication adherence. Previous studies also revealed that $60 \%$ of patients misunderstood what their physicians told them about medications (Remien, 1998). Moreover, patients rarely tell their physicians that they do not understand instructions 
because of time constraints, fearing to appear stupid, or not knowing what questions to ask (Meichenbaum and Turk, 1987). Therefore, pharmacists may be able to help HIV/AIDS patients manage their drug therapy.

This study was carried out in multiple clinic sites, two of which are in rural or suburban areas and one of which is in a metropolis; thus, the results may be applicable to patients in both rural and urban settings. However, differences in responses between the West Virginia and Maryland sites suggest that the characteristics of the site and/or its patients may be related to health beliefs and adherence. Hence, generalizations regarding adherence rates and health beliefs should be made cautiously.

\section{Conclusion}

The illness experiences of persons with HIV influence how they rate their chances of developing complications if they are not adherent to their medications. This further influences their medication adherence behaviors. Patients who have experienced AIDSrelated complications have higher perceptions of their susceptibility to further complications and have higher medication adherence rates than those earlier in the disease process. Difficulties in following doctors' instructions also affect HIV patients' medication adherence. The greater the perceived difficulty in following doctors' instructions, the lower the medication adherence rate. Patients' medication taking behaviors can be improved and the optimal treatment outcomes could be achieved by targeting issues specific to the individual patient, enhancing the relationship between patients and health care providers, and helping patients understand the negative consequences of poor adherence. 


\section{BIBLIOGRAPHY}

Aiken LS, West SG, Woodward CK et al. (1994). Health Beliefs and Compliance with Mammography-Screening Recommendations in Asymptomatic Women. Health Psychology. 13: 122-9.

Aizen I. (1985). From Intentions to Actions: A theory of planned behavior. In: Action Control: From Cognition to Behavior. Eds: Kuhl, J. and Beckman, J. Springer, Heidelberg.

Ajzen I, Fishbein M. (1980). Understanding Attitudes and Predicting Social Behavior. Prentice-Hall, Englewood-Cliffs, NJ.

Andersen RM, Newman JF. (1973). Societal and Individual Determinants of Medical Care Utilization in The United States. Milbank Mem Fund Q. 51: 95-124.

Andersen RM. (1995). Revisiting the Behavior Model and Access to Medical Care: Does it matter? J Health Social Behav. 36: 1-10.

Anonymous. (1996). New Drugs for HIV Infection. Med Lett Drugs Ther. 38: 35-7.

Baker J, Muma RD. (1991). Counseling Patients with HIV Infection. Physician Assistant. 15:40-8.

Bandura A., (1977). Self-Efficacy: Toward a Unifying Theory of Behavioral Change. Psychol Rev, 84, 191-215.

Bearden WO, Netemeyer RG, Teel JE. (1985). Measureemnt of Consumer Susceptibility to Interpersonal Influence. J of Consumer Research. 14: 473-81.

Becker M. (1974). The Health Belief Model and Personal Health Behavior. Health Educ Monogr. 2: 4.

Becker MH, Maiman LA. (1975). Sociobehavioral Determinants of Compliance with Health and Medical Care Recommendations. Medical Care. 13 (1): 10-24.

Becker MH, Maiman LA. (1980). Strategies for Enhancing Patient Compliance. J. of Community Health. 6: 113-35.

Becker MH, Rosenstock IM. (1987). Comparing Social Learning Theory and The Health Belief Model. In: Advances in Health Education and Promotion. Eds: Ward WB. Vol.2, JAI Press, Greenwich, CT. 
Berod T, Simon P. (1993). Outpatient Compliance with Zidovudine Therapy in French Polynesia. Am J Hosp Pharm. 50(3): 444.

Besch CL, Morse E, Simon P, et al. (1997). Preliminary Results of a Compliance Study within CPCRA 007 Combination Nucleoside Study. 4th Conference on Retroviruses and Opportunistic Infections. Washington DC. Abstract.

Bjornson DC, Oster CN, Cortese LM, et al. (1992). Aerosolized Pentamidine and Pneumocystis Carinii Pneumonia: patient compliance and outcomes. Ann Pharmacother. 26 (9): 1066-70.

Blalock SJ, DeVellis BM, Afifi RA et al. (1990). Risk Perceptions and Participation in Colorectal Cancer Screening. Health Psychology. 9(6): 792-806.

Borfitz D. (1994). Managing AIDS: The Hope And Limitations. Infusion. Nov: 9-13.

Boza RA, Milanes F, Salter V et al. (1987). Patient Noncompliance and Overcompliance. Postgrad Med. 81: 163-70.

Broers B, Morabia A, Hirschel B. (1994). A Cohort Study of Drug Users' Compliance with Zidovudine Treatment. Arch Intern Med. 154, May 23: 1121-7.

Carmel S, Shani E and Rosenberg L. (1994). The Role of Age and An Expanded Health Belief Model in Predicting Skin Cancer Protective Behaivior. Health Education Research. 9: 433-47.

Carpenter CCJ, Fischl MA, Hammer SM et al. (1996). Antiretroviral Therapy for HIV infection in 1996. JAMA. 276:146-54.

Centers for Disease Control and Prevention. (1997). HIV/AIDS Surveillance Report. 9:1.

Centers for Disease Control and Prevention. (1997). Report of The NIH Panel to Define Principles of Therapy of HIV Infection.1997.

Centers for Disease Control and Prevention. (1996). Update: Mortality Attributable to HIV Infection among Persons Aged 25-44 Years - United States, 1994. MMWR. 45: 12125.

Centers for Disease Control and Prevention. (1992). 1993 Revised Classification System For HIV Infection And Expanded Surveillance Case Definition For AIDS Among Adolescents And Adults. MMWR. 41 (No. RR-17).

Chubon SJ. (1989). Personal Descriptions of Compliance by Rural Southern Blacks: An exploratory study. J Compliance Health Care. 4(1): 23-38. 
Coe RM, Wessen A. (1965). Social-psychological Factors Influencing the Use of Community Health Resources. Am J Public Health. 55: 1024.

Cohen J. (1960). A Coefficient of Agreement for Nominal Scales. Educ Psychol Meas. 20:37.

Cohen J. (1988). Statistical Power Analysis for the Behavioral Sciences. Lawrence Erlbaum Associates, Publishers.

Cohen LG, Noormohamed SE. (1996). Pediatric HIV Infection: a primer for pharmacists. J Am Pharm Assoc. NS36: 580-95.

Colley CA, Lucas LM. (1993). Polypharmacy: the cure becomes disease. Gen Intern Med. 8(5): 278-83.

Conner M, Norman P. (1994). Comparing The Health Belief Model and The Theory of Planned Behavior in Health Screening. In: Social Psychology and Health: European Perspectives". Eds: Rutter DR and Quine L. Avebury, Brook field, VT.

Conrad P. (1985). The Meaning of Medications: Another look at compliance. Soc Sci Med. 20:29-37.

Cooper JK, Love DW, Raffoul PR. (1982). Intentional Prescription Nonadherence (noncompliance) by the Elderly. J Am Geriatr Soc. 30: 329-33.

Deeks SG; Smith M; Holodniy M et al. (1997). HIV-1 Protease Inhibitors: A review for clinicians. JAMA. 277: 145-53.

DiMatteo MR, DiNicola DD. (1982). The Compliance Problem: an introduction. In: Achieving Patient Compliance. The psychology of the medical practitioner's role. New York: Pergamon Press. 1-28.

DiMatteo RM, Firedman HS. (1982). Social Psychology and Medicine. Cambridge, MA. Oelgeschlager, Gunn, and Hain.

Dodds WB, Monroe KB. (1985). The Effect of Brand and Price Information on Subjective Product Evaluations. Advances in Consumer Research. 12: 85-90.

Donovan JL, Blake DR. (1992). Patient Non-Compliance: Deviance or Reasoned Decision-Making? Soc Sci Med. 34(5): 507-13.

Donovan JL. (1995). Patient Decision Making: the missing ingredient in compliance research. Int J Technol Assess Health Care. 11(3): 443-55. 
Dunbar J, Dunning EJ, Dwyer K. (1989). Compliance Measurement with Arthritis Regimen. Arthritis Care and Research. 2(3): S8-S16.

Edwards W. (1954). The Theory of Decision Making. Psychological Bulletin. 51: 380417.

Eldred L, Wu A, Chaisson RE, et al. (1997). Adherence to Antiretroviral Therapy in HIV Disease. 4th Conference on Retroviruses and Opportunistic Infections. Washington DC. Abstract.

Enger C, Graham N, Peng Y, et al. (1996). Survival from early, intermediate, and late stages of HIV infection. JAMA. 275: 1329-34.

Eraker SA; Kirscht JP; Becker MH. (1984). Understanding and Improving Patient Compliance. Ann Intern Med. 100:258-68.

Erdman RA, Horstman L, Van Domburg RT, et al. (1993). Compliance with the Medical Regimen and Partner's Quality of Life after Heart Transplantation. Qual Life Res. 2: 20512.

Evans RL, Halar EM, Bishop DS. (1986). Family Function and Treatment Compliance after Stroke. Int J Rehabil Res. 9: 70-2.

Feinstein AR. (1979). "Compliance Bias" and the Interpretation of Therapeutic Trials. In: Compliance in Health Care. Ed: Haynes RB, Taylor DW, Sackett DL. Baltimore, Johns Hopkins University Press. 309-22.

Felkey BG. (1995). Adherence Screening and Monitoring. Am Pharm. NS35(7): 42-51.

Ferketich S. (1991). Focus on Psychometrics: Aspects of item analysis. Research in Nursing \& Health. 14:165-8.

Finney JW, Friman PC, Rapoff, MA, et al. (1985). Improving Compliance with Antibiotic Regimens for Otitis Media: Randomized clinical trial in a pediatric clinic. Am J of Diseases of Children. 139: 89-95.

Fishbein M, Ajzen I. (1975). Belief, Attitude, Intention, and Behavior. Wiley, New York.

Fishbein M. (1967). Attitude and Prediction of Behavior. In: Readings in Attitude Theory and Measurement. Ed: Fishbein M. John Wiley \& Sons, Inc. New York.

Fleiss JL. (1981). Statistical Methods for Rates and Proportions. Ed 2. New York, John Wiley \& Sons.

Foulkes LM, Boggs SR, Fennell RS, et al. (1993). Social Support, Family Variables, and Compliance in Renal Transplant Children. Pediatric Nephrology. 7: 185-88. 
Friedman HS, DiMatteo RM. (1989). Health Psychology. Englewood Cliffs, NJ, Prentice Hall.

Gasbrro R. (1996) Pediatric AIDS. US Pharmacist. September: HS23-34.

Geletko SM, Ballard CR, Mathews WC. (1995). Health Beliefs and Discontinuation of Zidovudine Therapy. Am J Health-Syst Pharm. 52, Mar 1: 505-7.

Gerber KE. (1986). Compliance in the Critically Ill: an introduction to the problem. In: Gerber KE, Nehemkis AM. Eds: Compliance. The dilemma of the chronically ill. New York: Springer Publishing Company. 12-23.

Gibaldi M. (1996). Failure to Comply: a therapeutic dilemma and the bane of clinical trials. J Clin Pharmacol. 36(8): 674-82.

Glaxo Wellcome. (1996). Epivir® (lamivudine) Prescribing Information.

Gordis L. (1979). Conceptual and Methodologic Problems in Measuring Patient Compliance. In: Measurement of Compliance. Sackett DL, Haynes RB, Eds: Baltimore, MD: The Johns Hopkins University Press. 23-62.

Gordis L. (1996). Epidemiology. Ch4. W.B. Saunders Company.

Graham N, Jacobson LP, Kuo V, et al. (1994). Access to Therapy in The Multicenter AIDS Cohort Study, 1989-1992. J Clin Epidemiol. 47(9): 1003-12.

Green LW, Levine DM, Deeds SG. (1975). Clinical Trials of Health Education for Hypertensive Outpatients. Prev Med. 4: 417.

Green SB. (1991). How Many Subjects Does It Take to Do a Regression Analysis? Multivariate Behavioral Research. 26: 499-510.

Griffith S. (1990). A Review of The Factors Associated With Patient Compliance and The Taking of Prescribed Medicines. British Journal of General Practice. 40: 114-6.

Gulick RM, Mellors J, Havlir D, et al. (1996). Potent and Sustained Antiretroviral Activity of Indinavir (IDV) in Combination with Zidovudine (ADV) and Lamivudine(3TC). In: Program and abstracts of the Third National Conference on Human Retrovirus and Related Infections. Washington, DC, January 28-February 1, 1996. Washington, DC: American Society of Microbiology.

Hanley BE. (1996). Insurance Reimbursement Policies and AIDS Home Healthcare: Public and Private Financing Mechanisms. AIDS \& Public Policy Journal. Summer 1996; 11 (2): 89-103. 
Havlir DV, Richman DD. (1996). Viral Dynamics of HIV: implications for drug development and therapeutic strategies. Ann Intern Med. 124: 984-94.

Haynes BF, Panteleo G, Fauci AS. (1996). Toward an understanding of the correlates of protective immunity to HIV infection. Science. 271: 324-28.

Haynes RB. (1979). Determinants of compliance: The disease and the mechanics of treatment. In: Haynes RB, Taylor DW, Sackett DL, Eds: Compliance and Medical Care. Baltimore, MD. The Johns Hopkins University Press.

Haynes RB; Mckibbon KA; Kanani R. (1996). Systematic Review of Randomized Trials of Interventions to Assist Patients to Follow Prescriptions for Medications. Lancet. Aug 10; 348(9024): 383-86.

Hunt LM, Jordan B, Irwin S, et al. (1989). Compliance and The Patient's Perspective: Controlling symptom in everyday life. Cult Med Psychiatry. 13:315-34.

Institute of Medicine, National Academy of Sciences. (1986). Confronting AIDS: Directions for Public Health, Health Care, and Research.

Janz NK, Becker MH. (1984). The Health Belief Model: A decade later. Hlth Educat. Q.11:1-47.

Johnson SB. (1993). Chronic Diseases of Childhood: Assessing compliance with complex medical regimens. In: Krasnegor NA, Epstein L, Johnson SB, et al. Eds. Developmental Aspects of Health Compliance Behavior. New Jersey: Lawrence Erlbaum Associates. 1993; 157-84.

Kaplan RM, Simon HJ. (1990). Compliance in Medical Care: Reconsideration of selfpredictions. Ann Behav Med. 12: 66-71.

Landis JR, Koch GG. (1977). The Measurement of Observer Agreement for Categorical Data. Biometrics. 33:159.

Lane HC, Laughon BE, Falloon J, et al. (1994). Recent Advances in The Management of AIDS-Related Opportunistic Infection. Ann Intern Med. 120: 945-55.

Lau RR, Harman KA, Ware JE. (1986). Health as A Value: Methodological and theoretical considerations. Health Psychology. 5: 25-43.

Leventhal H, Cameron L. (1987). Behavioral Theories and the Problem of Compliance. Patient Education and Counseling. 10: 117-138. 
Lim LL. (1992). Estimation Compliance to an AIDS Clinical Trial from Serum Drug Levels: Application to an AIDS clinical trial of zidovudine. Biometrics. Jun 48(2): 61930 .

Litwin MS. (1995). How to Measure Survey Reliability and Validity. The Survey Kit. SAGE publications, Inc.

Meichenbaum D, Turk DC. (1987). Treatment Adherence: terminology, incidence, and conceptualization. In: Facilitating Treatment Adherence. A Practitioner's Guidebook. NY: Plenum Press. 19-40.

Meichenbaum D, Turk DC. (1987). Treatment Adherence: terminology, incidence, and conceptualization. In: Facilitating Treatment Adherence: A practitioner's guidebook. New York, NY: Plenum Press. 41-68.

Michael DW. (1986). AIDS and Patient Management: Legal, Ethical and Social Issues.

Morisky DE, Green LW, Levine DM. (1986). Concurrent and Predictive Validity of a Self-reported Measure of Medication Adherence. Medical Care. .24(1): 67-74.

Morris LS, Schulz RM. (1993). Medication Compliance: The patient's perspective. Clinical Therapeutics. 15(3): 593-606.

Morse EV, Simon PM, Coburn M, et al. (1991). Determinants of Subject Compliance Within An Experimental Anti-HIV Drug Protocol. Soc. Sci. Med. 32(10): 1161-7.

Muma RD, Ross MW, Parcel GS, et al. (1995). Zidovudine Adherence among Individuals with HIV Infection. AIDS Care. 7(4): 439-47.

Nau DP. (1997). A Perceived Value Framework For Explaining Patients' Intentions to Use Pharmaceutical Care Services. Doctoral Dissertation, University of Florida, Gamesville, FL.

Nunnally JC. (1978). Psychometric Theory. New York: McGraw-Hill.

O’Connor PG, Molde S, Henry S, et al. (1992). Human Immunodeficiency Virus Infection in Intravenous Drug Users: A model for primary care. Am J Med. 93: 382-5.

Osman L. (1996). The Patient Perspective: What should a new anti-asthma agent provide? Drugs. 52 Suppl 6: 29-35.

Pablos MA, Sterling TR, Frieden TR. (1996). Relationship Between Delayed Or Incomplete Treatment and All-Cause Mortality in Patients with Tuberculosis. JAMA. 276 (Oct.16): 1223-28. 
Pietroski NA. (1996). Treating HIV With Protease Inhibitors. Am Druggist. 10:50-57.

Pollard RB, Onorato M. (1995). An Approach to Antiretroviral Treatment of HIV Disease. New Approaches. Hosp Pract. 1995; 30 (suppl 1): 32-40.

Putnam DE, Finney JW, Barkley PL, et al. (1994). Enhancing Commitment Improves Adherence to a Medical Regimen. J. of Consulting and Clinical Psychology. 62(1): 19194.

Quinn TC. (1995). The Epidemiology of The Acquired Immunodeficiency Syndrome in The 1990s. Em Med Clin North Am. 13: 1-25.

Remien RH. (1998). Adhering to HIV Combination Therapy: The role of the pharmacist. Pharmacy Times. 5: 28-37.

Rimer BK. (1990). Perspectives on Intrapersonal Theories in Health Education and Health Behavior. In: Health Behavior and Health Education. Glanz F, Marcus-Lewis F, $\&$ Rimer BK (Eds). Jossey-Bass Publishers, San Francisco.

Robinson JP, Shaver PR, Wrightsman LS. (1991). Criteria for Scale Selection and Evaluation. In: Measures in Personality and Social Psychological Attitudes. The Academic Press, San Diego, CA.

Ronis DL, Harel Y. (1989). Health Beliefs and Breast examination behaviors: Analyses of linear structural relations. Psychology and Health. 3: 259-85.

Ronis DL, Kaiser MK. (1989). Correlates of Breast Self-examination in A Sample of College Women: Analysis of linear structural model. Journal of Applied Social Psychology. 19: 1068-84.

Ronis DL. (1992). Conditional Health Threats: Health Beliefs, Decisions, and Behaviors Among Adults. Health Psychology. 11(2), 127-34.

Rosenberg PS. (1995). Scope of The AIDS Epidemic in The United States. Science. 270: $1372-5$.

Rosenstock, IM. (1966). Why People Use Health Services. Milbank Med. Fund Quarterly. 44: 94-124.

Roxane Laboratories. (1996). Viramune ${ }^{\circledR}$ (nevirapine) Prescribing Information.

Rudd P, Tul V, Brown K, et al. (1979). Hypertension Continuation Adherence: Natural history and role as an indicator condition. Arch Intern Med. 139-545.

Rudd P. (1993). The Measurement of Compliance: Medication Taking. In: Developmental Aspects of Health Compliance Behavior. 
Samet JH, Libman H, Steger KA, et al. (1992). Compliance with Zidovudine therapy in Patients Infected with Human Immunodeficiency Virus, Type 1: A cross-setional study in a municipal hospital clinic. Am J Med. 92:495-502.

Sande MA, Volberding PA. (1990). The Medical Management of AIDS. Philadelphia, Pa: WB Saunders Co.

Schwarzer R. (1992). Self-efficacy Is The Adoption and Maintenance of Health Behaviors: Theoretical approaches and a new model. In: Self-efficacy: Thought Control of Action. 1-19. Ed: Schwarzer R. London, Hemisphere.

Sluijs EM, Knibbe JJ. (1991). Patient Compliance with Exercise: Different theoretical approaches to short-term and long-term compliance. Patient Education and Counseling. 17: 191-204.

Smith, S. (1996). A Longitudinal Study of Access and Drug Utilization in a Cohort with HIV Disease. Doctoral Dissertation, University of Michigan.

Somer E, Tucker CM. (1988). Patient Life Engagement, Spouse Marital Adjustment, and Dietary Compliance of Hemodialysis Patients. J Compliance Health Care. 3:57-65.

Spilker B. (1992). Methods of Assessing and Improving Patient Compliance in Clinical Trials. IRB. A Review of Human Subjects Research. May-Jun, 14(3): 1-6.

Stall R, Hoff C, Coates TJ, et al. (1996). Decisions to Get HIV Tested and to Accept Antiretroviral Therapies among Gay/Bisexual Men: Implications for secondary prevention efforts. J Acquir Immune Defic Syndr Hum Retrovirol. 11: 151-60.

Stimson GV. (1974). Obeying Doctor's Orders: A view from the other side. Soc Sci Med. 8: 97-104.

Streiner DL, Norman GR. (1995). Ch.8, Reliability. Health Measurement Scales. 2nd Edition. Oxford Medical Publications.

Sullivan SD, Kreling DH, Hazlet TK. (1990). Noncompliance with Medication Regimens and Subsequent Hospitalizations: A literature analysis and cost of hospitalization estimate. J Res Pharmac Econom. 2: 19-33.

Swindells S; Gendelman HE. (1996). The New Non-nucleoside Reverse Transcriptase Inhibitors. Infect Med. 13:715-9,731.

Tabachnick BG, Fidell LS. (1996). Multivariate Analysis of Variance and Covariance. In: Using Multivariate Statistics. New York:HarperCollins Publishers. 
Tseng AL. (1998). Compliance Issues in the Treatment of HIV Infection. Am J HealthSyst Pharm. 55:1817-24.

van der Plight J. (1994). Risk Appraisal and Health Behavior. In: Social Psychology and Health: European Perspectives. 131-151. Eds: Rutter D and Quine L. Brookfield, VT: Avebury.

Vogel MR. (1997). Drug News: Combination antiretroviral product simplifies HIV treatment. Pharmacy Today. 3(11): 6.

Wallston KA, Wallston B. (1981). Health Locus of Control Scales. In: Research with the Locus of Control Construct. 1: 70-81. Ed: Lefcourt H. New York, Academic Press.

Wood CM, Scheer LK. (1996). Incorporating Perceived Risk into Model of Consumer Deal Assessment and Purchase Intent. Advance in Consumer Research. 23: 399-404.

Woodward WC. (1996). Should Directly Observed Therapy Be Considered for Treatment of HIV? JAMA. Dec. 25, 276(24): 1956.

World Health Organization. (1996). AIDS Global Data. The Current Global Situation of The HIV/AIDS Pandemic. Weekly Epidemiological Record. 71: 361-68.

Zeithaml VA. (1988). Consumer Perceptions of Price, Quality, and Value: A means-end model and synthesis of evidence. Journal of Marketing. 52: 2-22. 


\section{APPENDIX A.}

CDC 1993 Revised Classification System for HIV Infection and Expanded AIDS Surveillance Case Definition System for AIDS Among Adolescents and Adults *

\begin{tabular}{|l|c|c|c|}
\hline & \multicolumn{3}{|c|}{ Clinical Categories (See Appendix B) } \\
\hline $\begin{array}{c}\text { CD4+ T-cell } \\
\text { Categories }\end{array}$ & $\begin{array}{c}\text { (A) } \\
\text { Asymptomatic, } \\
\text { acute HIV or PGL }\end{array}$ & $\begin{array}{c}\text { Symptomatic, not (A) } \\
\text { or (C) conditions }\end{array}$ & $\begin{array}{c}\text { AIDS-indicator } \\
\text { conditions }\end{array}$ \\
\hline$(1) \geq 500 / \mu \mathrm{L}$ & A1 & B1 & C1 \\
\hline$(2) 200-499 / \mu \mathrm{L}$ & A2 & B2 & C2 \\
\hline$(3)<200 / \mu \mathrm{L}$ & A3 & B3 & C3 \\
\hline
\end{tabular}

* The shaded cells illustrate the expanded AIDS surveillance case definition.

Source: Centers for Disease Control. 1993 revised classification system for HIV infection and expanded surveillance case definition for AIDS among adolescents and adults. MMWR 1992; 41 (No.RR-17). 


\section{APPENDIX B.}

\section{Clinical Categories Used in CDC 1993 Revised AIDS Surveillance Case Definition}

\section{Category A}

One or more of the conditions listed below occurring in an adolescent or adult with documented HIV infection. Conditions listed in categories B and C must not have occurred.

- Asympotmatic HIV infection

- Persistent generalized lymphadenopathy (PGL)

- Acute (primary) HIV infection with accompanying illness or history of acute HIV infection

\section{Category B}

Symptomatic conditions occurring in an HIV-infected adolescent or adult that are not included among conditions listed in clinical category $\mathrm{C}$ and that meet at least one of the following criteria: (a) the conditions are attributed to HIV infection or are indicative of a defect in cell-mediated immunity; or (b) the conditions are considered by physicians to have a clinical course or to require management that is complicated by HIV infection. Examples include, but are not limited to:

- Bacillary angiomatosis

- Candidiasis, oropharyngeal (thrush)

- Candidiasis, vulvovaginal; persistent, frequent, or poorly responsive to therapy

- Cervical dysplasia (moderate or severe)/cervical carcinoma in situ

- Constitutional symptoms, such as fever $\left(\geq 38.5^{\circ} \mathrm{C}\right)$ or diarrhea lasting $>1$ month

- Hairy leukoplakia, oral

- Herpes zoster (shingles), involving at least two distinct episodes or more than one dermatom

- Idiopathic thrombocytopenic purpura

- Listeriosis

- Pelvic inflammatory disease, particularly if complicated by rubo-ovarian abscess

- Peripheral neuropathy 


\section{Category C}

Any condition listed in the 1987 surveillance case definition for AIDS (or conditions added in the 1993 revision) and affecting an adolescent or adult. The conditions listed in category $\mathrm{C}$ are strongly associated with severe immunodeficiency, occur frequently in HIV-infected individuals, and cause serious morbidity or mortality.

Conditions listed in the 1987 AIDS surveillance case definition:

- Candidiasis of bronchi, trachea, or lungs

- Candidiasis, esophageal

- Coccidioidomycosis, disseminated or extrapulmonary

- Cryptococcosis, extrapulmonary

- Cryptosporidiosis, chronic intestinal (>1 month duration)

- Cytomegalovirus disease (other than liver, spleen, or nodes)

- Cytomegalovirus retinitis (with loss of vision)

- Encephalopathy, HIV-related

- Herpes simplex: chronic ulcer(s) (>1 month duration); or bronchitis, peumonitis, or esophagitis

- Histoplasmosis, disseminated or extrapulmonary

- Isosporiasis, chronic intestinal (>1 month duration)

- Kaposi's sarcoma

- Lymphoma, Burkitt's (or equivalent term)

- Lymphoma, immunoblastic (or equivalent term)

- Lymphoma, primary, of brain

- Mycobacterium avium complex or M. kansasii, disseminated or extrapulmonary

- Mycobacterium tuberculosis, disseminated or extrapulmonary

- Mycobacterium, other species or unidentified species, disseminated or extrapulmonary

- Pneumocystis carinii pneumonia

- Progressive multifocal leukoencephalopathy

- Salmonella septicemia, recurrent

- Toxoplasmosis of brain

- Wasting syndrome due to HIV

Conditions added to the AIDS surveillance case definition in the 1993 revision:

- Cervical cancer, invasive

- Mycobacterium tuberculosis, pulmonary

- Pneumonia, recurrent

Source: Centers for Disease Control. 1993 revised classification system for HIV infection and expanded surveillance case definition for AIDS among adolescents and adults. MMWR 1992; 41 (No.RR-17). 


\section{APPENDIX C.}

\section{Indications for the Initiation of Antiretroviral Therapy in the Chronically HIV-Infected Patient}

\begin{tabular}{|c|l|l|}
\hline Clinical Category & \multicolumn{1}{|c|}{$\begin{array}{c}\text { CD4+ T-cell Count } \\
\text { and HIV RNA }\end{array}$} & \multicolumn{1}{|c|}{ Recommendation } \\
\hline $\begin{array}{l}\text { Symptomatic (AIDS, thrush, } \\
\text { unexplained fever) }\end{array}$ & \multicolumn{1}{|c|}{ Any value } \\
\hline Asymptomatic & $\begin{array}{l}\text { CD4+ T-cells }<500 / \mu \mathrm{L} \text { or } \\
\text { HIV RNA }>10,000(\mathrm{bDNA}) \\
\text { or }>20,000(\mathrm{RT}-\mathrm{PCR})\end{array}$ & $\begin{array}{l}\text { Treatment should be offered. Strength } \\
\text { of recommendation is based on } \\
\text { prognosis for disease-free survival and } \\
\text { willingness of the patient to accept } \\
\text { therapy. }\end{array}$ \\
\hline Asymptomatic & $\begin{array}{l}\text { CD4+ T-cells }>500 / \mu \mathrm{L} \text { and } \\
\text { HIV RNA < 10,000 (bDNA) } \\
\text { or <20,000 (RT-PCR) }\end{array}$ & $\begin{array}{l}\text { Some experts would delay therapy } \\
\text { and observe; however, some experts } \\
\text { would treat. }\end{array}$ \\
\hline
\end{tabular}




\section{APPENDIX D. Cover Letter}

\section{Dear Patient,}

Do you or someone you know find it difficult to manage all of your medications? Would you like to tell us about your experiences with HIV medications? We are attempting to learn more about how people with HIV view their disease and their medications. This information could be useful in helping us and other health care providers understand how people with HIV cope with using multiple medications and why some people stop using their medications.

We have attached an anonymous questionnaire about your feelings towards HIV and your medications. If you do not want to complete this survey, you do not have to. Although we hope that you answer all of the questions, you do not have to answer any question that makes you uncomfortable. There are no right or wrong answers - just provide the answers that best match your feelings. The survey should take about ten minutes to complete.

When you have finished the questionnaire, please seal it in the attached envelope and return it to us or just drop it in a mail box. The envelope is addressed to our colleagues at the West Virginia University School of Pharmacy who are helping us analyze the results of the survey, but since your name is not on the survey they will not know your identity. Your participation in this survey will not directly affect the care that you receive, but may help us design more effective treatment plans for persons with HIV.

If you have any questions about this survey, please do not hesitate to ask. Thank-you,

Xin Gao, B.S. Doug Drevets, M.D. R. Wesley Farr, M.D.

Melanie Fisher, M.D. Gina Marie Foglia, M.D. Rashida Khakoo, M.D. 


\section{APPENDIX E.}

\section{Instructions for the physician:}

Step 1. Ensure that patient meets inclusion criteria:

$>$ confirmed diagnosis of HIV infection;

$>$ using antiretroviral therapy for at least one month;

$>$ age 18 years or older;

$>$ mentally competent.

Step 2. Please indicate the disease category of the patient as A, B, or $\mathrm{C}$ in the box on the first page of questionnaire according to the criteria on the following page.

IMPORTANT NOTE ---- The disease category should be selected based upon whether the patient has EVER experienced the indicator conditions, rather than his/her current status.

Step 3. Please give the survey to the patient.

Questions may be directed to Xin Gao (304-293-6991) or Dr. David Nau (304-293-1453). Thank you. 


\section{APPENDIX F. Questionnarie}

Medication Use Survey 
1. Which of the following medicines have you taken during the past month (check all that apply)? Please indicate whether you take one of the common doses or take a different amount of the medication. On the following page, please list any other medications that you take on a regular basis.

Medication

$\square$ Combivir $^{\circledR}$ :

(zidovudine and lamivudine)

$\square$ Crixivan ${ }^{\circledR}$ :

(indinavir)

$\square$ Epivir $^{\circledR}$ :

(lamivudine, 3TC)

$\square \operatorname{Hivid}^{\circledR}$ :

(zalcitabine, DDC)

$\square$ Invirase ${ }^{\circledR}$ :

(saquinavir mesylate, $\mathrm{SQV}$ )

$\square$ Norvir $^{\circledR}$ :

(ritonavir)

$\square$ Rescriptor $^{\circledR}$ :

(delavirdine mesylate)

$\square$ Retrovir $^{\circledR}$ :

(zidovudine, AZT, ZDV)

$\mathcal{a}$ Videx $^{\circledR}$ :

(didanosine, DDI)

$\square$ Viracept $^{\circledR}$ :

(nelfinavir mesylate)

$\square$ Viramune ${ }^{\circledR}$ :

(nevirapine)

$\square$ Zerit $^{\circledR}$ :

(stavudine, d4T)
Common Dose

Other (Please Specify)

1 tablet, 2 times a day

2 capsules, 3 times a day

1 tablet, 2 times a day

1 tablet, 3 times a day

3 capsules, 3 times a day

6 capsules, 2 times a day

4 tablets, 3 times a day

2 capsules, 3 times a day

2 tablets, 2 times a day

3 tablets, 3 times a day

1 tablet, 2 times a day

1 capsule, 2 times a day 
Other medications that you take on a regular basis:

Medication

How many doses you take each day

2. Has a physician ever told you that you have AIDS?

$\square$ Yes $\square$ No

3. What was your lowest CD4+ count ever?
$\square 0-99$
$\square 100-199$
$\square 200-499$
$\square \geq 500 \quad \square$ don't know

4. What is your most recent CD4+ count?
$\square 0-99$
$\square 100-199$
$\square 200-499$
$\square \geq 500$
$\square$ don't know

5. What was your highest viral load ever?
$\square<20,000$
$\square 20,000-750,000$
$\square>750,000$
$\square$ don't know

6. What is your most recent viral load?
$\square<20,000$
$\square 20,000-750,000$
$\square>750,000$
$\square$ don't know

7. How often do you visit or contact your physician?

$\square$ More than once a month

$\square$ Once a month

$\square$ Once every 2 - 3 months

$\square$ Once every 4 - 5 months

$\square$ Once every half a year or longer 
8. How long have you been taking medications for HIV/AIDS?

$\square 0$ - 1 month

$\square 2$ - 3 months $\square 4$ - 6 months

$\square$ More than 6 months

9. How do you pay for your HIV medications? (Check all that apply)

$\begin{array}{lll}\square \text { Medicaid } & \square \text { Private Insurance } & \square \text { Ryan White Consortium } \\ \square \text { Drug Company } & \square \text { Self-Pay } & \square \text { Other }\end{array}$

10. If you do NOT take your HIV medications as directed, how would you rate the chances of your disease getting worse ( i.e. develop AIDS-related complications)?

$\square$ Very Low $\quad$ LLow $\quad$ Dlntermediate $\quad \square$ High $\quad \square$ Very High

11. If you take your HIV medications as directed, how would you rate the chances of your disease getting worse (i.e. develop AIDS-related complications)?

$\square$ Very Low $\quad$ LLow $\quad$ Intermediate $\quad \square$ High $\square$ Very High

Please indicate to what extent you agree or disagree with the following statements.

$\begin{aligned} & \text { Strongly Disagree Neutral Agree Strongly } \\ & \text { disagree }\end{aligned}$
agree

12. Compared to other illnesses, HIV/AIDS is NOT very serious.

13. If I do NOT take my HIV medications as prescribed, I will become very sick.

14. If I take my HIV medications as prescribed, I will still become very sick.

15. Taking HIV medications as prescribed can prolong my life. 
$\begin{aligned} & \text { Strongly Disagree Neutral Agree Strongly } \\ & \text { disagree }\end{aligned}$
agree

16. Taking HIV medications interferes a great deal with my normal activities.

17. The HIV medications that I'm taking are too expensive for me.

18. Taking HIV medications exactly as prescribed decreases the chances of my illness getting worse.

19. HIV medications cause annoying side effects.

20. Taking HIV medications or having side effects from them has made me feel more nervous or depressed than usual.

21. Dealing with the side effects of HIV medications is stressful.

22. The HIV medications that I'm taking will improve my health (i.e. raise immune system, cause weight gain, etc.). ....

23. HIV medications will work more effectively if I take them only when I am feeling bad.

24. It is difficult to follow doctors' instructions on HIV medications. .........

25. Taking my HIV medications is worth the hassle.

26. Overall, would you say your experiences with HIV medications have been:

$\square$ Negative $\square$ Somewhat Negative $\square$ Neutral $\square$ Somewhat Positive $\square$ Positive 
27. Do you ever forget to take any of your medications? ...... $\square$ Yes $\quad \square$ No

28. Are you always careful about taking your medications? ... $\square$ Yes $\square$ No

29. When you feel better do you sometimes stop taking your medication? $\square$ Yes $\square$ No

30. Sometimes if you feel worse when you take the medication, do you stop taking it ? .................................... $\square$ Yes $\square$ No

31. Over the past two days, how many doses of your HIV medications have you missed?

32. Over the past two weeks, how many doses of your HIV medications have you missed?

33. Have you purposefully chosen to discontinue any of your HIV medications?

$\square$ Yes $\square$ No

If Yes, what medication(s) did you discontinue?

Why did you discontinue these medications (check all that apply)?

$\square$ their side effects are intolerable.

$\square$ they are not helpful.

$\square$ they are expensive.

$\square$ taking them is complicated and inconvenient for me.

$\square$ refilling prescriptions or regular clinic check is a burden on me.

$\square$ I heard/observed worsening of HIV symptoms in others taking their medications.

$\square$ I heard/observed positive results in others not taking their medications.

$\square$ I want to reserve them for when I am feeling worse.

Other Reasons: Please tell us as much as you can in the space below.

PLEASE GO TO THE NEXT PAGE. 

A. Age:
$\square 18-24$
$\square 25-34$
$\square 35-44$
$\square 45$ or older

B. Gender: $\square$ Male $\square$ Female

C. Ethnic Origin:

$\begin{array}{lll}\square \text { White } & \square \text { Black or African-American } & \square \text { American Indian } \\ \square \text { Hispanic } & \square \text { Asian or Pacific Islander } & \square \text { Other }\end{array}$

D. What is the highest level of education that you have completed?

$\square$ Less than 9th grade

$\square$ Some college, no degree

$\square$ Graduate or professional degree

E. What was your approximate household income before taxes, in 1997? $\square$ 9th to 12th grade

$\square$ Bachelors degree

\section{E. What was your approxinate household income before taxes, in $1997 ?$}
$\square$ less than 10,000
$\square 10,000-19,999$
$\square 20,000-29,999$
$\square 30,000-49,999$
$\square 50,000$ or more

If you would like to tell us anything else about medications for HIV, please write them below. 


\section{Thank You for taking time to complete this survey. Your responses are very important and we truly appreciate your effort and cooperation. Please return the questionnaire in the self-addressed envelope. No postage is required.}




\section{APPENDIX G.}

\section{Patients' Comments}

1. I feel guilty and stressed for not taking my medications as prescribed. But when I take them as prescribed, I feel bad. So, I take them once a day. This makes me feel evil, ungrateful, bad, etc.

2. Triple therapy is by far the best option so far. If we can find a way to stop diarrhea, (that will be) great.

3. I know taking HIV medication as prescribed can prolong my life.

4. They are too expensive, it is hell dealing with my HMO.

5. Viracept needs some sort of coating: taste disgusting since it dissolves immediately.

6. Side effects are horrible! Adherence can be very difficult due to a variety of circumstances. However, I feel it's worth taking the medications because I feel they definitely prolonged my life.

7. Having the doctors who are easy to communicate with makes taking medications much easier. Pharmacists also play a key role in this communication process.

8. People should take the medications because it does help and all you have to do is think positive and other people should help as think positive about the medications. Thank you.

9. I reduced the dosage so that my supply would last longer as I don't have the money to afford all three antiretrovirals in my regimens. (Also) I discontinued DDI/DDC because of side effects manifested by severe pain in liver.

10. Some of my answers regarding tolerance and/or compliance were specific to another period of time in my life - I've been on AZT for 8 years. Therefore the answers may not reflect my current tolerance/compliance. But all in all, I'm grateful to have the medications/care that I get - I'm thankful for each day and every thing I have. People in this country have no idea how good they have it.

11. If it wasn't for them, I don't think any of us infected would be alive with out the blessing of God! Thank You!! 
12. I very seldom miss a dose but often find myself taking them an hour or two earlier or later than scheduled.

13. Less pills to take at one time could make it more easy to carry with you.

14. I'm still experiencing a very low appetite, very sore knee and elbow joints. Very difficult scheduling medication around meals. I hardly miss my doses of medication now by taking of 3 crixivan twice a day instead of 2 three times a day.

15. I feel very ill from the side effects more so than ever in my life. I feel weak. My muscles, legs and shoulders hurts. I am always nauseated. I feel sick at my stomach. The diarrhea stays more than goes away. I get terrible headaches. The sun makes me break out in a rash I get very sick if I get too hot. My muscles twitch in my arms and legs. This is new. I drink a lot of water but my back (kidneys) hurt sometimes. I drink more water. My urine looks like oil in the water at times and smells real strong of the medications. But I'm very careful about my medications and never miss one dose.. I am committed.

16. With this drug cocktail I became very ill: lost weight and became hospitalized. It was a bad experience for me. The medications that I am taking right now have been wonderful. I have my health back along with my life. If it weren't for my doctors: Dr. hernandez, Dr. Szego and my pharmacist Christine Teague, I wouldn't be here.

17. Thanks God for the treatment I get.

18. If you were prescribe by your doctor to take medicine you should take it for a longer life and feel better.

19. Patient says "taking my medicines makes me feel like I have a chance to live longer."

20. I don't believe any HIV medications are ultimately life-saving: they prolong rather than eliminate the risks of end-stage. So I comply with treatment with great hope or faith in their efficacy. Yes, the regiments are a hassle, but when I think of all the people in the Third World who die their lack of access to any of these medications I keep my complaints to my myself.

21. I think the medications work and has done a good deed for me. More people need to know about it. It is like getting a second chance of life.

22. To me, my medications were a blessing to me. Thank you. 


\section{RESUME}

\section{Kin Gao}

1064 Van Voorhis Rd. J-312

Morgantown, WV 26505
Telephone: (304) 293-4338

Fax: (304) 293-2529

E-mail:xgao4@wvu.edu

1996 - Present

\section{EDUGATION}

Master of Science Student in Department of Pharmaceutical Systems and Policy, School of Pharmacy, West Virginia University, Morgantown, WV.

Thesis title: The relationship of disease severity, health beliefs, and medication adherence among HIV patients.

$1990-1994$

Bachelor of Science, China Pharmaceutical University, Nanjing, China.

\section{TITERIENGE}

1998 - Present Research Assistant, Prevention Research Center, West Virginia University

$1997-1999$ A study about the relationship between disease severity, health beliefs, and treatment adherence among HIV patients

Summer 1997 Summer Intern, developing and evaluating smoking cessation interventions in the Prevention Research Center, West Virginia University

1994-1996

Pharmacist, Pharmacy Department, Cardiovascular Institute and FuWai Hospital, Chinese Academy of Medical Sciences, Beijing, China.

\section{Pratimions}

Horn K, Dino G, Momani A, Gao X. Not-On-Tobacco: Smoking Cessation Program. Poster Presentation at the American Association for Health Plans 2nd Annual Meeting. San Diego, CA, January 1999.

Gao X, Nau D, Rosenbluth S. The relationship of disease severity, health beliefs, and medication adherence among HIV patients. Presented as a poster at the 145th APhA Annual Meeting. Miami, FL, March 1998.

Horn K, Meckstroth D, Dino G, Gao X. WV Middle and High School Coaches Smokeless Tobacco Survey: A Summary of Findings. Prevention Research Center of West Virginia University, 1998.

Horn K, Dino G, Kamal-Bahl S, Gao X, Momani A, and Meit H. Year 2000 Youth Tobacco Assessment. Prevention Research Center of West Virginia University, 1997. 
Gao X, Chen J. Strategies for transnational management in pharmaceutical enterprises. Journal of Pharmaceutical Economy. 1995, 2: 27-30.

Chen J, Gao X. Suggestion to national policies about improving the transnational management in pharmaceutical enterprises. Journal of China Pharmacy Field. 1994, $1: 15-6$.

Pu' Th

Horn K, Gao X, Dino G. Determinants of Youth Tobacco Use in West Virginia: A Comparison of Smoking and Smokeless Tobacco Use. Submitted to the American Journal of Drug and Alcohol Abuse.

Horn K, Dino G, Gao X, Momani A. Not-On-Tobacco: Smoking Cessation Program. Submitted to the American Journal of School Health.

C. IITETS

- A Cost-Benefit Analysis and Quality-of-Life Assessment for the Use of Filgrastim (G-CSF) in HIV/AIDS Patients With Antiretrovirals-Induced Neutropenia

- Using Time Series Analysis to Evaluate Trends in Medicare and Medicaid Payments on Nursing Home Care and Home Health Care: 1975 - 1995

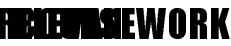

Project Evaluation and Decision Making, Pharmacoeconomics, Health Outcome Research, Applied Pharmacoeconomics \& Outcome Research, Microeconomics, Econometrics, Public Health Epidemiology, Managed Care and Quality Assessment, Health Care Organizations, Pharmaceutical Marketing, Marketing Strategies for Health Care Organizations, Consumer Behaviors, Marketing Management, Secondary Data Analysis, Research Design and Data Analysis, multivariate Analysis.

\section{GIDARENGY}

Statistical Analysis: SPSS, JUMP, \& SAS

Statistical Analysis Package for Economics: EVIEWS, @Risk, GAMS

Decision Analysis: Tree-Age, @Risk

Survey Development: SurveyPro

Other Proficiencies: Microsoft Excel, Word Perfect, Microsoft Word, MacWrite, and Power Point

\section{PLTiaghing}

- American Pharmaceutical Association

- International Society for Pharmacoeconomics and Outcomes Research 


\section{REFERENGES}

Suresh Madhavan, Ph.D.

Associate Professor and Chair

Department of Pharmaceutical Systems and Policy

School of Pharmacy

West Virginia University, PO Box 9510 HSCN

Morgantown, WV 26506

Telephone: (304) 293-1652

Fax: (304) 293-5483

E-mail: $\quad$ smadhava@wvuhsc1.hsc.wvu.edu

Sidney A. Rosenbluth, Ph.D.

Professor

Department of Pharmaceutical Systems and Policy

School of Pharmacy

West Virginia University, PO Box 9510 HSCN

Morgantown, WV 26506

Telephone: (304) 293-1832

Fax: (304) 293-5483

E-mail: $\quad$ srosenbluth@hsc.wvu.edu

David Nau, Ph.D.

Assistant Professor

Department of Pharmaceutical Systems and Policy

School of Pharmacy

West Virginia University, PO Box 9510 HSCN

Morgantown, WV 26506

Telephone: (304) 293-1453

Fax: (304) 293-5483

Email:_dnau@hsc.wvu.edu

Geri Dino, Ph.D.

Associate Chair

Department of Community Medicine

West Virginia University, PO Box 9005 HSCS

Morgantown, WV 26506

Telephone: (304) 293-1898

Fax: (304) 293-8624

E-mail: gdino@wvu.edu 